$$
\text { PNNL- - } 11420
$$

\title{
Laser Ablation/Ionization Characterization of Solids: Second Interim Progress Report of the Strategic Environmental Research Development Program
}

\section{RECEIVED \\ DEC 171997 \\ OSTI}

by

W. P. Hess, B. A. Bushaw, M. I. McCarthy, J. A. Campbell, S. D. Colson Pacific Northwest National Laboratory*

PO Box 999, Richland, WA 99352

and

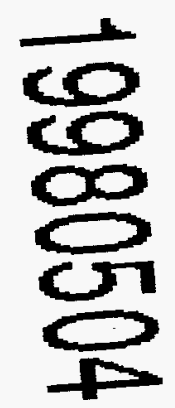

J. T. Dickinson

Washington State University

Department of Physics

Pullman, WA 99164-2814 USA

DISTRIBUTION OF THIS DOCUMENT IS UNLIMITE oh MASTLR

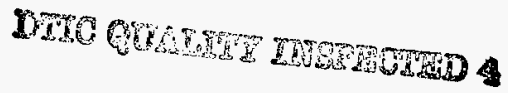

*Pacific Northwest National Laboratory is operated for the U. S. Department of Energy by

Battelle under Contract No. DE-AC06-76RLO 1830. 


\section{DISCLAIMER}

This report was prepared as an account of work sponsored by an agency of the United States Government. Neither the United States Government nor any agency thereof, nor any of their employees, makes any warranty, express or implied, or assumes any legal liability or responsibility for the accuracy, completeness, or usefulness of any information, apparatus, product, or process disclosed, or represents that its use would not infringe privately owned rights. Reference herein to any specific commercial product, process, or service by trade name, trademark, manufacturer, or otherwise does not necessarily constitute or imply its endorsement, recommendation, or favoring by the United States Government or any agency thereof. The views and opinions of authors expressed herein do not necessarily state or reflect those of the United States Governmeat or any agency thereof. 


\section{TABLE OF CONTENTS}

PAGE

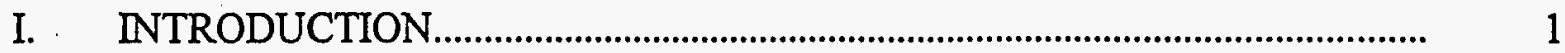

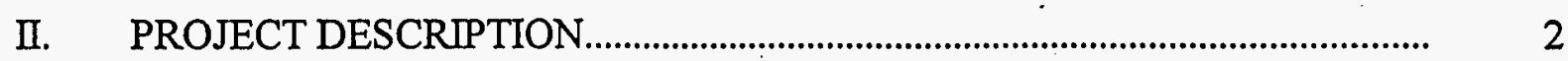

III. ACCOMPLISHMENTS......................................................................................

A. Laser Ablation Mass Spectrometry............................................................ 12

a. Resonant Laser Ablation.................................................................. . 13

b. Nonresonant Laser Ablation............................................................ $\quad 14$

c. Theoretical Studies................................................................... 16

B. Development of Diode-Laser-Based Excitation Schemes for CW Resonance Ionization of Technitium........................................................... 18

a. Optimal Laser Ionization Schemes.................................................. 19

b. Frequency Doubling the External Cavity Diode Laser....................... 21

c. Locking to Atomic Reference Signals.................................................. 22

d. Frequency Shifting..................................................................... 23

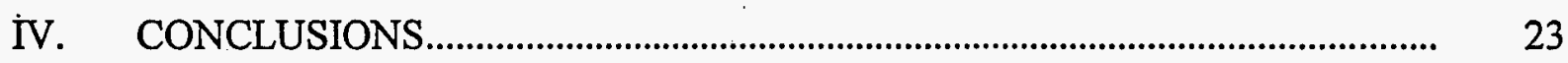

A. Acknowledgment................................................................................ 24

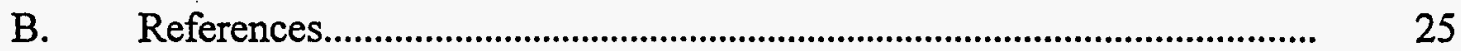

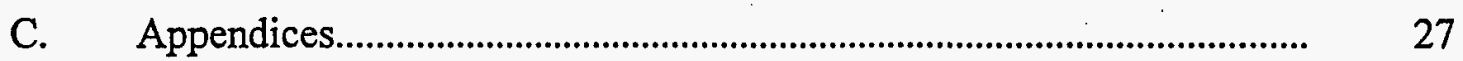

a. Appendix A: List of Publications and presentations resulting from SERDP supported Work.................................................................. 27

b. Appendix B: Relevance to the Department of Defense................... 31 


\title{
Laser Ablation/Ionization Characterization of Solids: Second Interim Progress Report of the Strategic Environmental Research Development Program
}

(October, 1996)

\author{
W. P. Hess, B. A. Bushaw, M. I. McCarthy, J. A. Campbell, S. D. Colson \\ Pacific Northwest National Laboratory \\ PO Box 999 Richland, WA 99352
}

\author{
J. T. Dickinson \\ Washington State University \\ Department of Physics \\ Pullman, WA 99164-2814 USA
}

\section{INTRODUCTION}

The Department of Energy is undertaking the enormous task of remediating defense wastes and environmental insults which have occurred over 50 years of nuclear weapons production. It is abundantly clear that significant technology advances are needed to characterize, process, and store highly radioactive waste and to remediate contaminated zones. In addition to the processing and waste form issues, analytical technologies needed for the characterization of solids, and for monitoring storage tanks and contaminated sites do not exist or are currently expensive labor-intensive tasks. This report describes progress in developing sensitive, rapid, and widely applicable laser-based mass spectrometry techniques for analysis of mixed chemical wastes and contaminated soils.

The remediation of defense waste and the long-term disposal of high-level mixed wastes requires chemical analysis of the waste streams. Efficient analytic methods are needed to characterize the chemical classes and concentrations of a wide variety of waste materials. Tank and crib waste sites contain broad distributions of radioisotopes, metals, TRU's, aromatic organic compounds, halogenated hydrocarbons, nitrates, chelating agents, chromates, and ferrocyanides. The chemical speciation and concentration of these materials must be determined in order to design effective cleanup strategies and to perform risk analysis. Additionally, the high concentrations of radioactive waste materials, in tanks and cribs, provide an energetic driving force that continuously transforms mixed waste through complex kinetic pathways; hence, 
analyses need to be made in a timely fashion. Current methods require as much as six months to analyze a single waste tank core sample. This report outlines our initial efforts at developing rapid analysis techniques, which may be extended to on-line field measurements.

\section{PROJECT DESCRIPTION}

We are developing analysis techniques based on laser ablation mass spectroscopy (LAMS), matrix assisted laser desorption ionization (MALDI), and resonance enhanced multiple photon ionization (REMPI). Laser ablation is used to vaporize solid materials and the resulting pulsed plumes are analyzed using mass spectrometry or resonant laser ionization techniques. Analysis of even complex, multicomponent mixtures can be performed rapidly and requires very little sample. This is necessary for the analysis of many environmental samples and hazardous wastes. The concentrated laser ablation plumes are probed using multiphoton ionization time-of-flight mass spectroscopy. This is a versatile and sensitive technique of high mass resolution which can distinguish between compounds of similar masses and between isotopes. For certain important atomic isotopes, the superb spectral resolution of multistep resonant ionization, can detect minute $(\sim 100$ attogram) samples and differentiate between a minor isotope buried in a $10^{10}$ fold excess of the naturally occurring isotope.

The advantages of the LAMS approach include: Small sample requirements, minimum sample preprocessing, minimum waste generation, and reliable technology. However, several uncertainties are introduced by the ablation process. For instance, it is not clear how well the composition of the ablated (gaseous) products reflects the sample composition; some sample components can be preferentially ablated. We have used several approaches to determine in more detail the mechanisms and consequences of laser ablation on model waste compounds and on relevant wide-band-gap inorganic materials. A detailed study of the ablation of a major waste tank constituent (sodium nitrate) has been completed. LAMS analysis of a variety waste tank constituents has also been performed and very encouraging results for the analysis of ethylenediaminetetraacetic acid and hydroxyethylenediaminetriacetic acid (EDTA and HEDTA both chelating agents) and waste simulant have been obtained. The technique of matrix assisted laser desorption ionization (MALDI), a variant of the LAMS technique, has been used to aid the analysis of the more complicated waste compounds. The MALDI technique involves adding a "matrix" compound to the waste sample to aid the laser vaporization and ionization process. Once vaporized, the analyte/matrix 
plume contains both positive and negative ions which often provide complementary information.

For certain critical trace elements, it is also important to focus on the method of ionization of the ablated material. Technetium- 99 has been identified as a significant ground water contaminant at a number of locations on the Hanford site. Because of its long half-life (214,000 years), high fission yield, and high rate of mobility in the subsurface, Tc- 99 is considered a hazardous radioisotope waste. Furthermore, Tc- 99 can be used as a critical path isotope for performance assessment of nuclear waste isolation barriers. Because Tc-99 is a long-lived pure beta-emitter, routinely available radiochemical-counting methods do not provide adequate sensitivity for use of Tc-99 as a performance assessment tool. However, the long half-life of Tc-99 does make it an ideal case for high-sensitivity detection by laser resonance ionization methods. Current efforts have designed optimal excitation schemes, using resonances that overlap the emission wavelengths of reliable diode and titanium-sapphire laser sources. Improvements on this methodology, are expected to ultimately result in a fieldportable, routine analytical technology capable of rapid, accurate and sensitive measurements.

There are three major objectives of this research. First, to develop general and sensitive techniques for determining the molecular speciation of organics and inorganics in tank wastes and those chemisorbed on mineral soil substrates. Second, to develop new multiphoton-ionization schemes, based on reliable solid-state diode lasers, for detection of Tc-99 and other environmentally relevant atomic species. Third, to transfer this new knowledge to other applied DOE and DoD analytical programs such as the MARS and Hanford-site characterization programs. This report has been written in partial fulfillment of the third objective.

\section{ACCOMPLISHMENTS}

\section{A. Waste Compound Analysis by Matrix Assisted Laser Desorption Ionization}

We have recently used MALDI for the molecular analysis of a variety of known waste compounds. The MALDI technique works by embedding a low concentration of a high molecular weight (HMW) molecules in an excess of a carboxylic acid matrix. The matrix usually has a strong absorption resonant with the laser ablation wavelength such that the initial pulse energy is readily deposited into the matrix rather than into the 
analyte. The subsequent vaporization of the matrix produces isolated gas-phase biomolecules, often without significant fragmentation. The vaporized matrix provides another benefit by enhancing the chemical ionization of the nascent gas phase species. When MALDI is combined with TOFMS one can measure an entire mass spectrum in a single analytical step requiring only a few microseconds. Since the MALDI process produces ions directly, very little material is required and thus MALDI is an efficient micro sampling technique that minimizes radiation exposure for the analysis of highly radioactive samples.

Chelating compounds such as ethylenediaminetetracetic acid (EDTA) and $\mathrm{N}-(2-$ hydroxyethyl)ethylenediaminetriacetic acid (HEDTA), are receiving renewed analytical interest. Large quantities of EDTA and HEDTA (approximately 240 and 1500 tons, respectively) have been used in defense-related activities at the DOE Hanford site. ${ }^{1}$. The chelators form water-soluble complexes with most heavy metals, thereby enhancing the migration of heavy metals in soils. For example, studies at Oak Ridge National Laboratory demonstrated that EDTA caused the low-level migration of ${ }^{60} \mathrm{Co}$ from intermediate-level liquid waste disposal pits and trenches. ${ }^{2}$. Another study at the Maxey Flats commercial low level waste disposal site revealed that Pu-EDTA and ${ }^{60} \mathrm{Co}$-EDTA migrated. ${ }^{3}$ Analytical methods for chelators and organic acids, in radioactive wastes, generally involve derivatization and gas chromatography ${ }^{4}$ coupled with mass spectrometry or liquid chromatography. ${ }^{5}$ The MALDI technique has several advantages over other methods when applied to analysis of low molecular weight (LMW) compounds. ${ }^{6}$ Due to the nature of the gentle ionization processes, chelators and other non-volatile species should remain intact during analysis without the need for time-consuming derivatization procedures.

We have used MALDI-TOF to examine anions, organic acids, and chelators. Samples of EDTA, HEDTA, citric acid, NTA and several of the inorganic anions including sulfate, phosphate, nitrate, and nitrite were analyzed, in high and low salt concentrations and over a wide $\mathrm{pH}$ range, to reflect conditions present in such wastes. Samples containing high salt concentrations can dramatically decrease MALDI sensitivity thus severely deteriorating analytical results. ${ }^{7}$ In order to improve MALDI sensitivity for high salt content samples, we have processed some samples using cation exchange. In addition, we performed MALDI on mixtures of these compounds to simulate the combinations of compounds found in complex mixed wastes. All data were obtained using a linear TOF instrument with a nominal mass resolution of $\mathrm{m} / \Delta \mathrm{m}=600$, positive and negative ion detection modes and a channeltron ion detector with an amplification of $10^{5}$. An internal $337 \mathrm{~nm}$ nitrogen laser, of $3 \mathrm{~ns}$ pulse duration, is used to induce the desorption/ionization process. 
We tried several standard matrix molecules (Fumaric, maleic, and succinic acids) and, as noted by other workers, ${ }^{8}$ found 2,5 dihydroxy benzoic acid (DHB) to be the most efficient. In most cases, matrix molecules were mixed in water to a concentration of $10 \mathrm{mg} / \mathrm{ml}$ which is approximately a saturated solution. Analyte molecules were dissolved in water to the same concentration and combined, in various proportions, with the matrix solution. One (1.0) microliter of sample was applied to each spot on the sample tray. The MALDI spectrometer can be programmed to scan the laser beam focus across each individual sample spot. In all analyses, 100 evenly spaced laser pulses were collected and averaged per sample spot. Since we are interested in determining the constituents of complex sample mixtures we performed MALDI on mixtures of several analytes including: oxalic acid, citric acid, ammonium sulfate, and ammonium nitrate. We parameterized the MALDI technique for analysis of LMW molecules by measuring the effects of varying the matrix to analyte molar ratio, the laser fluence, and the sample $\mathrm{pH}$, on the analyte base peak ion signal. For most analyses, the matrix to analyte molar ratio was roughly 100:1. In one study, the ratio of matrix to analyte was varied systematically from 1000:1 to 0.1:1. The $\mathrm{pH}$ was varied for both citric acid and HEDTA analytes before the samples were applied to the sample tray. The $\mathrm{pH}$ values were adjusted using trifluoroacetic acid $(0.1 \%)$, purified water, and $1 \%$ ammonium hydroxide to approximately 2,5 , and 10 , respectively.

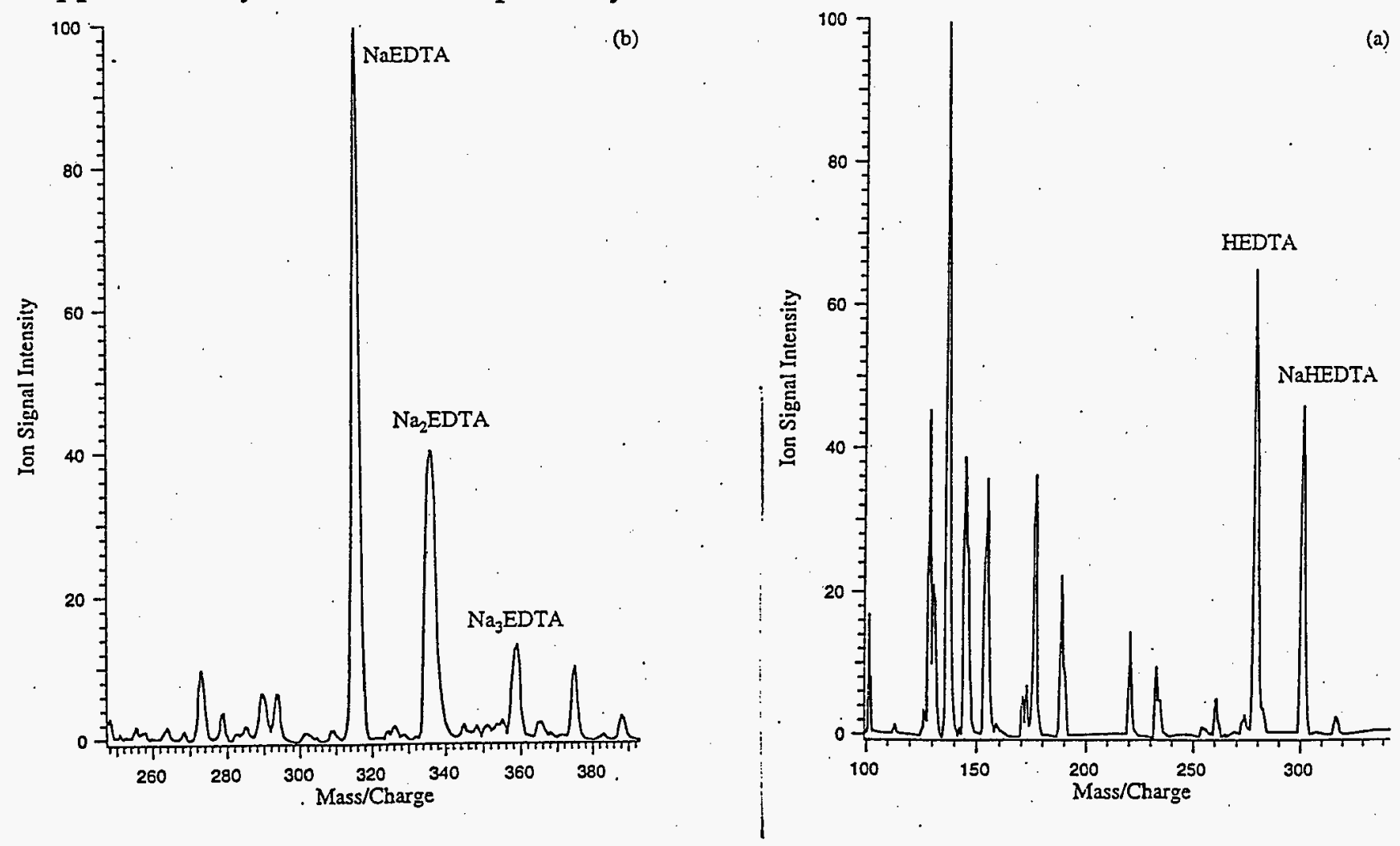

Figure 1. Positive ion MALDI spectra for (a) HEDTA and (b) EDTA in DHB at a matrix to analyte molar ratio of 100 to 1 . The protonated $[\mathrm{M}+\mathrm{H}]^{+}$, and sodiated $[\mathrm{M}+\mathrm{Na}]^{+}$are identified. Note the progression of sodiated peaks in $(b)$ at $m / z=315,337$, and 359 . The peaks at $\mathrm{m} / \mathrm{z}=137,155$, and 177 are attributed to ionized matrix species as described in the text. 
Figure 1 shows the positive ion MALDI spectrum of HEDTA and EDTA. The positive ion MALDI mass spectra of the chelators typically have strong base peaks indicative of the protonated $[\mathrm{M}+\mathrm{H}]^{+}$, and sodium adduct $[\mathrm{M}+\mathrm{Na}]^{+}$peaks. The EDTA spectrum displays multiple sodium adducts $[\mathrm{M}+\mathrm{nNa}]+$. At lower $\mathrm{m} / \mathrm{z}$ strong ion signals attributable to the $\mathrm{DHB}$ matrix are observed; $[\mathrm{DHB}-\mathrm{OH}]^{+}$at $m / z 137,[\mathrm{DHB}+\mathrm{H}]^{+}$at 155 , and $[\mathrm{DHB}+\mathrm{Na}]^{+}$at 177 . Figure 2 shows the negative ion MALDI mass spectrum of citric acid, the strong negative ion signal is attributed to the deprotonated intact molecule $[\mathrm{M}-\mathrm{H}]^{-}$at $\mathrm{m} / \mathrm{z}=191$. Figure 2 illustrates how little matrix interference can be present in the negative ion detection mode as only a single strong matrix peak is evident at $m / z=153,[D H B-H]-$. The analytes studied and the $m / z$ values and assignments of the ions observed in positive and negative ion MALDI-MS are shown in Table 1. Inspection of Table 1 reveals an interesting feature; the amine-based chelating compounds yield strong signals in the positive ion mode while the small organic acids and oxyanions yield strong signals in the negative ion mode. This effect is most easily rationalized on the basis of relative acidities and ion stabilities.

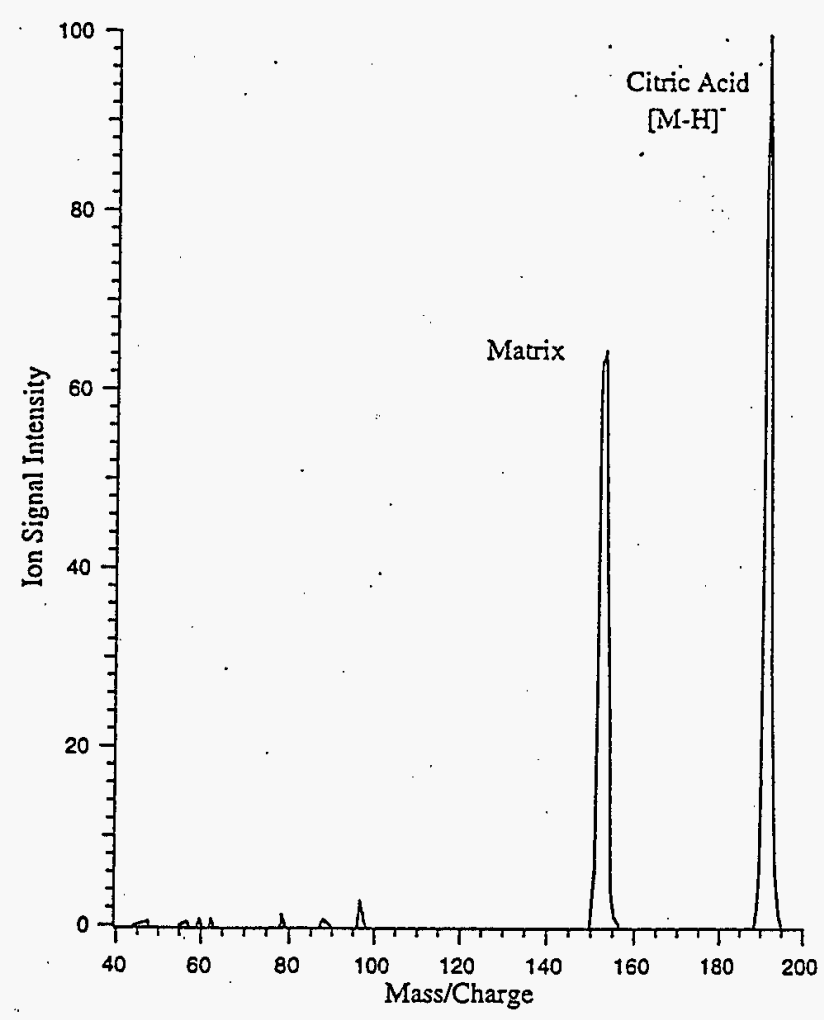

Figure 2. Negative ion MALDI mass spectrum for citric acid in DHB matrix at a matrix to analyte ratio of 1 to 100 . The spectra displays only two significant peaks, the $[\mathrm{M}-\mathrm{H}]-$ base peak at $\mathrm{m} / \mathrm{z}=191$ and the single matrix base peak [DHB-H]at $\mathrm{m} / \mathrm{z}=153$. The 'clean' mass spectrum and distinct lack of fragment or adduct peaks is characteristic of the negative ion MALDI of small molecules. 
Table 1. Positive and Negative ions observed by MALDI-TOF MS

Analyte Molecular Weight Ions Observed (m/z)

$(-)$

Sodium Nitrate 85

Sodium Nitrite 69

Oxalic Acid 90

Fumaric Acid 116

Maleic Acid 116

Succinic Acid 118

Ammonium Sulfate

Citric Acid 192

IDA 134

HEDTA $\quad 278$

EDDA $\quad 176$

NTA 191

EDTA 292

$62\left[\mathrm{NO}_{3}\right]^{-}$
$46\left[\mathrm{NO}_{2}\right]^{-}$
$89[\mathrm{M}-\mathrm{H}]^{-}$
$115[\mathrm{M}-\mathrm{H}]^{-}$
$115[\mathrm{M}-\mathrm{H}]^{-}$
$117[\mathrm{M}-\mathrm{H}]^{-}$
132

$191[\mathrm{M}-\mathrm{H}]^{-}$

\section{$97\left[\mathrm{HSO}_{4}\right]^{-}$}

$\begin{array}{lc}157[\mathrm{M}+\mathrm{Na}]^{+} & 173[\mathrm{M}+\mathrm{K}]^{+} \\ 279[\mathrm{M}+\mathrm{H}]^{+} & 201[\mathrm{M}+\mathrm{Na}]^{+} \\ 177[\mathrm{M}+\mathrm{H}]^{+} & 199[\mathrm{M}+\mathrm{Na}]^{+} \\ 192[\mathrm{M}+\mathrm{H}]^{+} & 199[\mathrm{M}+\mathrm{Na}]^{+} \\ 293[\mathrm{M}+\mathrm{H}]^{+} & 315[\mathrm{M}+\mathrm{Na}]^{+} \\ 337[\mathrm{M}+2 \mathrm{Na}]^{+} & 359[\mathrm{M}+3 \mathrm{Na}]^{+}\end{array}$

An important experimental consideration in MALDI analysis is the matrix:analyte molar ratio. For smaller molecules it has been suggested that a ratio of 100:1 to 1,000:1 is optimal. ${ }^{6}$ This ratio contrasts with typical matrix:analyte ratios of 1,000 to $10,000: 1$ for HMW species. ${ }^{9}$ Figure 3 shows a graph of the base peak ion signal intensity versus the matrix to analyte molar ratio for the range 1000:1 to 0.1:1(negative ion mode).

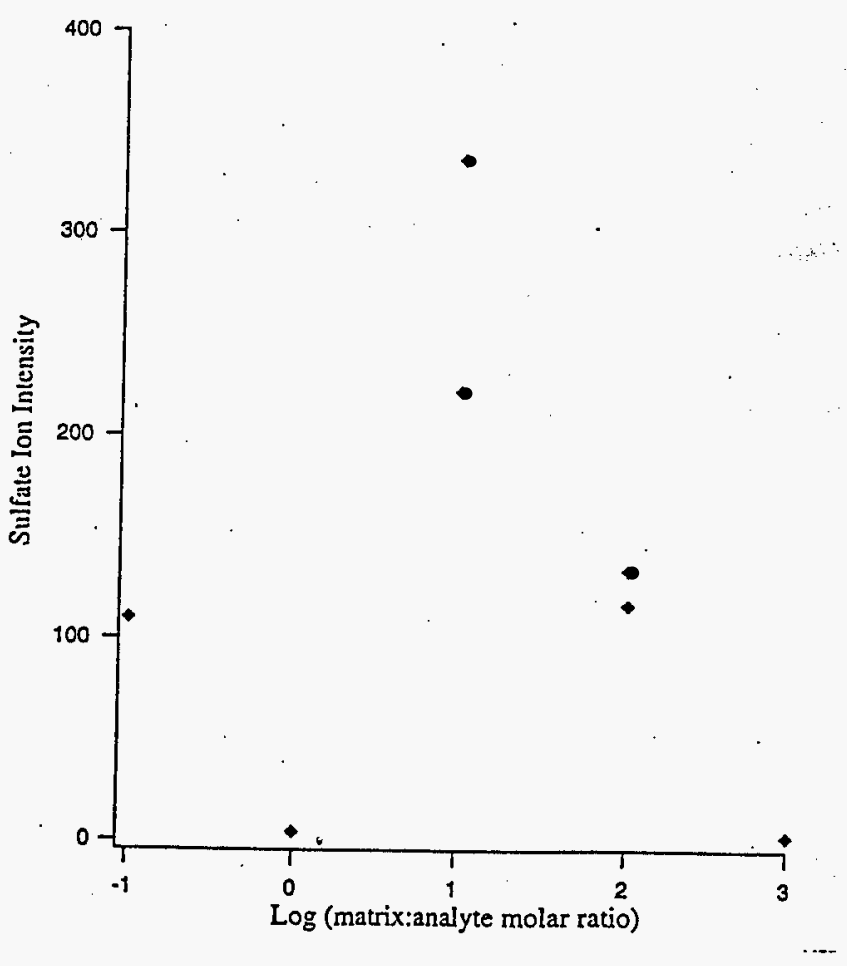

Figure 3. The integrated negative ion signal intensity versus the matrix to analyte molar ratio. The ion signal for citric acid [M-H]in DHB matrix over the matrix:analyte molar ratio range of $1,000: 1$ to $0.1: 1$. Although strong signals are observed in the range $10: 1$ and $1: 10$, results were more consistent for the molar ratio of 100:1. 
It appears from this figure that for. sulfate ion a matrix:analyte molar ratio of 100:1 provides a good signal and our empirical observation is that the best signal to noise is obtained at this ratio. We note however that strong but less consistent signals are obtained at the lower matrix to analyte ratios of 10:1 and even at ratio's as low as 0.1:1. For certain waste analysis applications, such low ratio's may be useful. For example, the analysis of radioactive samples may not allow a full dissolution of contaminates in a waste stream. In this case, the application of a top layer of matrix material, followed by standard MALDI mass spectrometry could determine the adsorbed contaminant. Although the optimum matrix to analyte ratio differed for the various analytes, each analyte displayed a linear correlation similar to that of sulfate with increasing signal for increasing analyte fraction.

The range of suitable samples was further evaluated by changing the $\mathrm{pH}$ of the solution using trifluoroacetic acid and ammonium hydroxide. Figure 4 displays the base peak signal strength for samples containing citric acid and HEDTA prepared at three different $\mathrm{pHs:} 0.1 \%$ trifluoroacetic acid ( $\mathrm{pH} \sim 2$ ), Milli-Q water ( $\mathrm{pH} \sim 5$ ), and $1 \%$ ammonium hydroxide ( $\mathrm{pH} \sim 10$ ). All six samples were analyzed using both positive and negative ion detection modes. The strongest signal for all analyte ions was from samples of the highest $\mathrm{pH}$ regardless of detection mode polarity. The increase in base peak intensity. with $\mathrm{pH}$ is most marked for the citric acid as the (M-H)- ion at $m / z$ 191. The material contained in mixed waste storage tanks is often characterized by high $\mathrm{pH}$ so this result is an unexpected positive for our analysis efforts.

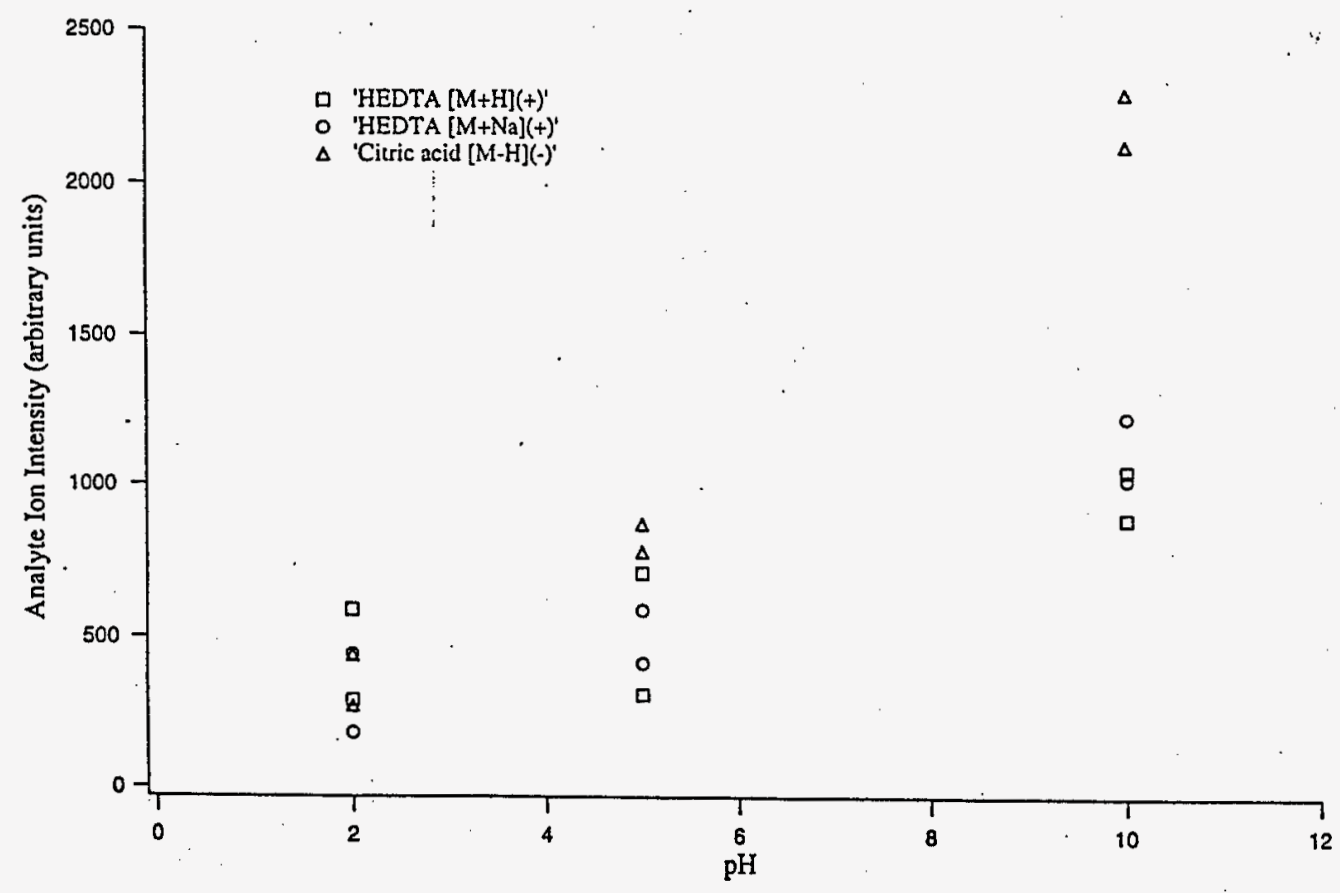

Figure 4. The influence of sample $\mathrm{pH}$ on integrate base peak intensity for citric acid and HEDTA analytes. The triangle symbols $(\Delta)$ designate citric acid in the negative ion mode $[\mathrm{M}-\mathrm{H}]^{-}$; the crosses $(+)$indicate the protonated HEDTA signal $[\mathrm{M}+\mathrm{H}]^{+}$; and the open circles $(\mathrm{O})$ designate the signal from the HEDTA sodium adduct $[\mathrm{M}+\mathrm{Na}]^{+}$. All three base peaks increase monotonically with $\mathrm{pH}$ over the range $\mathrm{pH}=2$ to $\mathrm{pH}=10$. 
Hazardous waste is often a very complex mixture containing dozens of compounds. It was anticipated that, at the lowest matrix to analyte molar ratios, multiple analytes might interfere with one another, or that some analytes would preferentially associate with the matrix, resulting in poor sensitivity. Figure 5 shows the negative ion MALDI spectrum of a relatively equimolar mixture of citric acid, oxalic acid, ammonium sulfate, and sodium nitrate with DHB matrix (matrix to analyte ratio of $\sim 1: 4$ ). All four analytes are readily observable although the nitrate ion signal at $m / z=62$ is considerably weaker than the three other analyte ion signals.

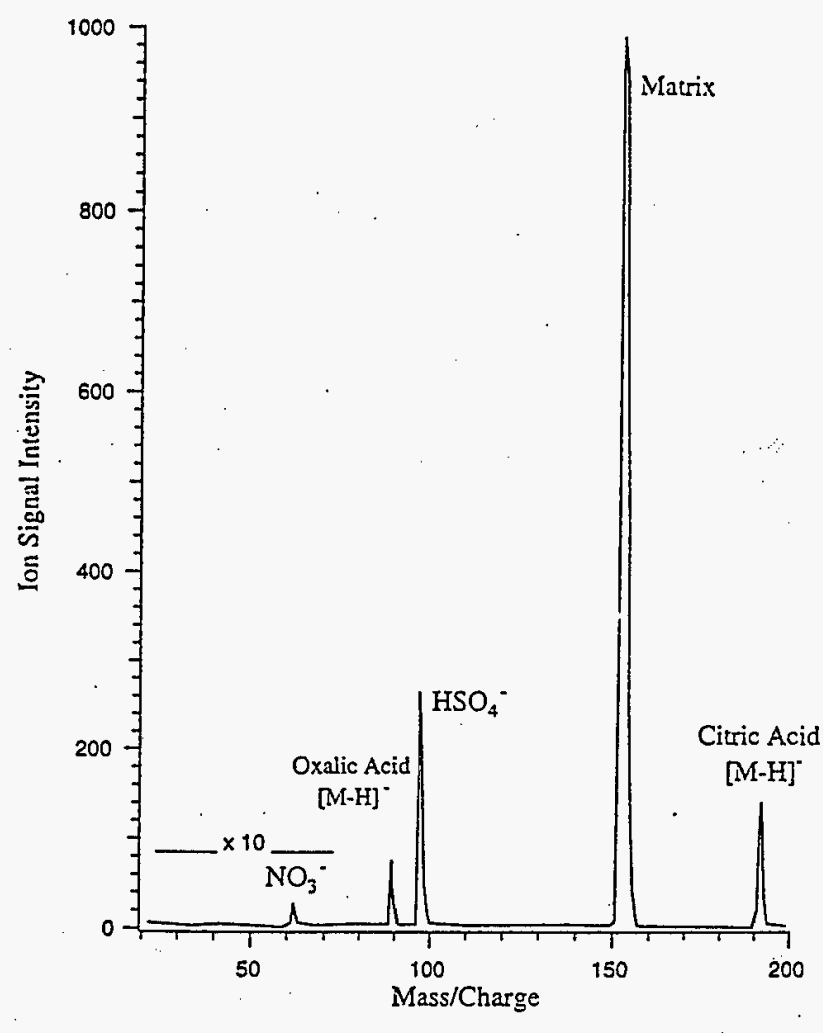

Figure 5. Negative ion MALDI spectrum of the analyte mixture consisting of equimolar concentrations of ammonium nitrate, oxalic acid, ammonium sulfate, citric acid and matrix (DHB). The matrix: analyte molar ratio is $\sim 4: 1$. It is notable that all four analytes produce detectable signals although the intensity $\mathrm{NO}_{3}-$ peak is significantly weaker than for the sulfate or organic acid analytes.

In an attempt to increase detection sensitivity in the analysis of samples containing or heavily contaminated with sodium or other alkali salts, we used an ion exchange resin to remove metal cations. Figure 6 displays the MALDI mass spectrum of sodium sulfate (before the ion exchange process) and ammonium sulfate after ion exchange. The absolute ion signal intensity of the $\mathrm{HSO}_{4}^{-}$base peak increases by factor of 140 . In addition the low mass "noise" is reduced with respect to the matrix ion signal at $\mathrm{m} / \mathrm{z}=137$. The base peak intensity was typically one to two orders of magnitude larger following ion exchange for the same quantity of analyte material. 

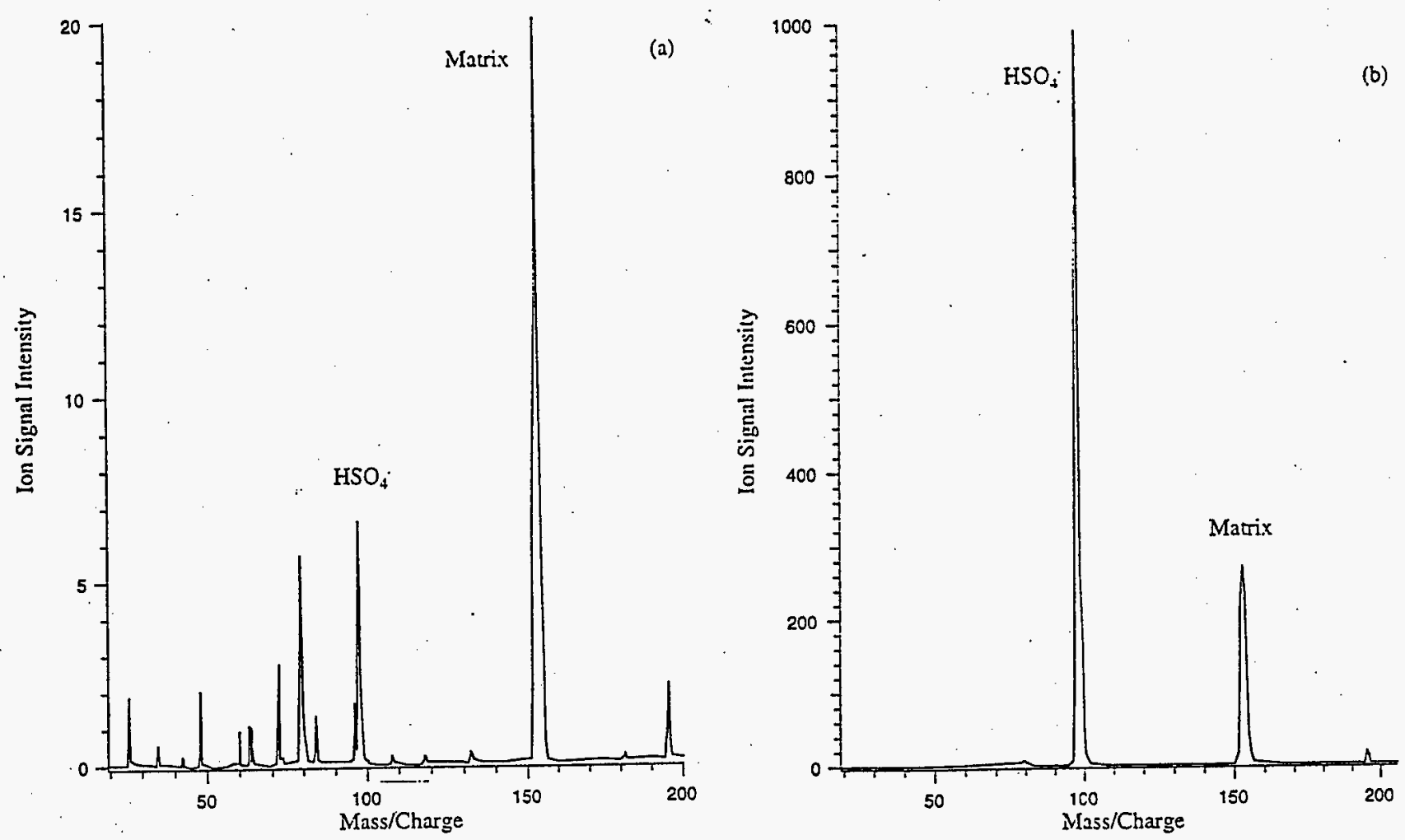

Figure 6. The negative ion MALDI spectrum of sodium sulfate before (a) and after (b) ion exchange. The $\mathrm{HSO}_{4}$ - base peak increases by a factor of 140 while the matrix ion base peak increases by a factor of 15 . Note the change in scale between (a) and (b). Sodium sulfate at a concentration of $10 \mathrm{mg} / \mathrm{ml}$ was analyzed in DHB and compared with the MALDI signal produced after processing through an ammonium form ion exchange column (see text).

Low molecular weight but thermally non-labile species, while amenable to MALDI analysis, provide unique challenges and significant technical differences exist between low and high mass regimes. Many HMW biomolecules contain several acidic and basic functional groups. The amphoteric nature of the large molecules results in strong MALDI signals in both negative and positive ion channels. For smaller molecules either the positive or negative ion channel may be favored. Consider the detection of the organic acids listed in Table 1; these molecules are readily deprotonated forming stable anions. We may reasonably expect strong $[\mathrm{A}-\mathrm{H}]^{-}$base peaks for organic acids. The results in Table 1 confirm this expectation. Similarly, the stable . oxyanions $\mathrm{NO}_{3}^{-}, \mathrm{NO}_{2}^{-}$, and $\mathrm{HSO}_{4}^{-}$are readily observed in the negative ion channel. In studies of small proteins and peptides, Zhu et al. found that the positive ion signal of MALDI was strongly enhanced by the presence of basic amino acids in the chain. In that work, it was argued that a solution phase pre-proton transfer mechanism is responsible for the enhanced positive ion signals. ${ }^{10}$ Similarly, our target chelating compounds EDTA, HEDTA, and EDDA 
are amine derivatives (i.e. good bases) which form stable adducts with $\mathrm{H}^{+}$and $\mathrm{Na}^{+}$leading to strong base peak signals in the positive ion channel.

Sodium ion adduction is often observed in MALDI, even for samples that do not contain sodium. ${ }^{11}$ In these cases, the sodium impurity is introduced through minor contamination of the matrix material. Sodium adduction competes efficiently with proton adduction at low levels of contamination. For samples containing a significant sodium component, such as $\mathrm{Na} 4 \mathrm{EDTA}$, we expect and observe a strong [EDTA $+\mathrm{Na}]^{+}$peak. We also observe the adduct series [EDTA $+\mathrm{nNa}]^{+}, \mathrm{n}=1-4$. Although multiple adduction of sodium is rare ${ }^{11}$ such species may reasonably be expected for a tetra-dentate chelator such as EDTA. The series of peaks at $\mathrm{m} / \mathrm{z}=315,337$, and 359 form a very characteristic pattern which strongly over determines the data set needed for detection of EDTA in solid samples. This is significant in that prior attempts at detection of chelators have proven quite difficult as the techniques of laser desorption ionization (LDI), and secondary ion mass spectrometry (SIMS) produce severely fragmented mass spectra. ${ }^{12}$

Figure 6 displays the relationship between MALDI sensitivity and sodium contamination. A possible mechanism for the reduced analyte ion yield involves the stealing of charge by both neutral $\left(\mathrm{Na}^{\circ}\right)$ and ionized $\left(\mathrm{Na}^{+}\right)$sodium atoms. The ionization potential of isolated sodium neutral is $5.1 \mathrm{eV}$ significantly lower that of either the matrix or the analyte. An excess of $\mathrm{Na}^{\circ}$ in the desorption matrix or plume could react or exchange charge with positively charged matrix or analyte, thus neutralizing analyte molecules and their ionization source. Since $\mathrm{Na}^{\circ}$ requires only $\sim 5 \mathrm{eV}$ to ionize, we may expect significant $\mathrm{Na}^{+}$concentrations in the desorbed plume. Collisions of $\mathrm{Na}^{+}$in the matrix of plume with negatively charged analyte molecules will rapidly neutralize these species as well. Hence, high sodium concentrations appear capable of simultaneously degrading both positive and negative ion yields. There are a variety of other plausible mechanisms for signal degradation by sodium salts.

In our efforts to apply MALDI to the analysis of high sodium content samples we removed sodium by cation exchange. The exchange of $\mathrm{NH}_{4}{ }^{+}$for $\mathrm{Na}^{+}$yielded a sensitivity increase of a factor of roughly 100 . It is anticipated that by using this ion exchange process a wide variety of small molecules contained in high salt content mixtures, can be easily analyzed by MALDITOF MS. Similarly the simultaneous detection of combinations of analytes is promising for obtaining semiquantitiative analysis of more complex mixtures. Future efforts will be directed at advancing quantitative aspects of waste analysis measurements because, at present, ion signals are often erratic. Progress toward quantitative analysis of HMW species has occurred only recently for well characterized samples. ${ }^{6,13-18}$ The difficulties encountered in attempts 
to obtain quantitative yields are due to the many factors which determine MALDI efficiency such as matrix/analyte effects, laser wavelength and power, morphological effects in sample crystallization, 19,20 and the complex nature of the MALDI technique. As yet, most of the operative mechanisms involved in MALDI are poorly understood. ${ }^{11,21-25}$ Nonetheless, recent progress using internal standards, ${ }^{6,13}, 17,18,26$ data analysis techniques, ${ }^{16}$ and comatrices ${ }^{14}$ is encouraging and we expect that, with more work, MALDI will become a reliable quantitative technique for solid waste analysis.

\section{A. LASER ABLATION MASS SPECTROMETRY}

A modified ultrahigh vacuum (UHV) mass spectrometer has been used to characterize individual waste compounds and waste simulant using the LAMS technique. Using this apparatus, the optimal laser-ionization frequency and pulse duration has been determined for detection of selected molecular species in the UV region between 50,000 and 37,600 wavenumbers ( $\mathrm{cm}-1)$. In particular, specific ionization schemes for desorbed species NO and CO have been determined. Laser pulse durations of $10 \mathrm{~ns}, 5 \mathrm{~ns}$ and 60 ps have been investigated for nitrate waste compounds. Excellent speciation of waste compounds EDTA, HEDTA, and succinic acid has been obtained using matrix assisted laser desorption ionization and additional studies building on these successes are in progress. To explore the details of laser ablation we conducted an in-depth LAMS study of sodium nitrate; a major Hanford-site tank waste component.

Sodium nitrate is a by-product of the chemical processes used to extract plutonium and as such constitutes a large fraction of Hanford-site tank waste. Over 150,000 tons of sodium nitrate are believed to be contained in the radioactive tank and crib waste and analysis of such wastes must account for the effects of this compound on the analysis technique. ${ }^{10}$ From the standpoint of molecular chemical analysis, solid $\mathrm{NaNO}_{3}$ is an excellent test of the LAMS method: Although the molecular formula is simple, yielding straightforward mass spectrometric analysis, the electronic and crystal structures are complex and complicated dynamics are likely during laser ablation. Indeed, the molecular speciation of salts such as sodium nitrate has proved difficult for LAMS and other analytical techniques. This is due, in part, to the ionic nature of the material which leads to facile plasma formation and the subsequent reactions of molecular species present in the ablation plume. For these and other reasons, we selected sodium nitrate for a detailed investigation by LAMS and other analysis techniques. 
We have used several approaches to explore the various dynamical regimes of UV ablation of sodium nitrate. Important experimental parameters including laser wavelength, power, and pulse duration for both the ablation and the ionization lasers were systematically investigated. The ablation laser wavelength was tuned from near $266 \mathrm{~nm}$ to $193 \mathrm{~nm}$ covering a region in which the material optical properties range from nearly transparent to very strongly absorbing. ${ }^{27}$ Different ablation mechanisms were found to dominate for resonant versus non-resonant laser ablation. The relative importance of each mechanism was also found to depend upon the condition of the sodium nitrate sample. For example, resonant ablation of a pristine sample of crystalline sodium nitrate produces molecular fragments at much higher yields than does longer wavelength nonresonant ablation. However, after exposing the sample to high radiation fluxes or electron bombardment, to simulate radiation damage as would be found in real waste samples, equally high yields can be obtained for either resonant or nonresonant ablation. The increased ablation yield of radiation damaged samples is likely due to defect-mediated mechanisms. ${ }^{28}$ To understand the resonant ablation mechanisms, we performed ab initio calculations on crystalline sodium nitrate, and isolated $\mathrm{NO}_{3}, \mathrm{NO}_{2}{ }^{-}$, and $\mathrm{NO}_{3}{ }^{-}$. The results of these calculations reveal the details of the laser ablation mechanism for resonant excitation of crystalline sodium nitrate. ${ }^{3}$

\section{Resonant Laser Ablation}

We have completed an investigation of the laser desorption of NO from single crystal sodium nitrate following pulsed 213-nm excitation of the $\pi^{*} \leftarrow \pi_{2}$ absorption band localized on the nitrate anion. The excitation laser flux was maintained at low levels (< $2 \mathrm{MW} / \mathrm{cm}^{2}$ ) to obtain product distributions free of secondary interactions following fragment ejection from the crystal surface. Neutral NO is the predominant desorption product although a smaller yield of neutral $\mathrm{O}_{2}$, much less than the stoichiometric ratio, is also observed. No significant desorption of $\mathrm{NO}_{2}$ or $\mathrm{Na}$ is detected under low laser fluence. ${ }^{29}$ At low fluence, no plasma is formed and the NO photodesorption yield is found to be linear with desorption laser power indicating that single photoabsorption events lead to fragment ejection. The desorption yield is enhanced by roughly a factor of 1000 for resonant excitation (213-nm) over nonresonant excitation (266-nm) on a perphoton basis. We determined the relative vibrational, rotational, and translational energy distributions of the neutral NO photoproducts to be 1.0:0.4:0.3:0.3:0.2 for the $v=0: 1: 2: 3: 4$ levels indicating significant vibrational excitation of the product NO. The vibrational product state distribution indicates that $\mathrm{NO}$ desorption is the final step of a photochemical process (exciton decay) that results from decomposition of $\mathrm{NO}_{3}^{*}$ on or near the crystal surface. ${ }^{29}$ The rotational state populations and translational energy 
distributions are well characterized by thermal distributions at the substrate temperature of 293K. The dissociation mechanism differs from that reported for dissociation of gas phase ions due to the stabilization of the ions by the crystalline field. The role of bulk exciton migration is unclear at present however, an ongoing effort to measure the desorption quantum yield may address this issue. We are currently investigating the contribution of defect absorption and exciton migration, to the overall reaction mechanism, by measuring the wavelength dependence of the $\pi^{*} \leftarrow \pi_{2}$ absorption band, and by laser polarization studies which exploit the birefringence of the sodium nitrate crystal.

\section{Nonresonant Laser Ablation}

For nonresonant laser ablation higher fluences are required for observable molecular emission. The principle neutral product observed by exposing single crystal sodium nitrate to 248-nm excimer laser radiation is still NO (at fluences of approximately $80 \mathrm{~mJ} / \mathrm{cm}^{2}$ as measured using a quadrupole mass spectrometer). The intensity and identity of the ablated products however, are a strong function of the laser fluence and previous sample exposure. ${ }^{30}$ In particular, a strong incubation effect is observed, with weak emission intensities during the early stages of irradiation which grow dramatically with continued irradiation. Figure 7 displays a sigmoid shaped emission versus laser exposure curve that characterizes the incubation behavior.

No Emission During Incubation at $750 \mathrm{~mJ} / \mathrm{cm}^{2}$

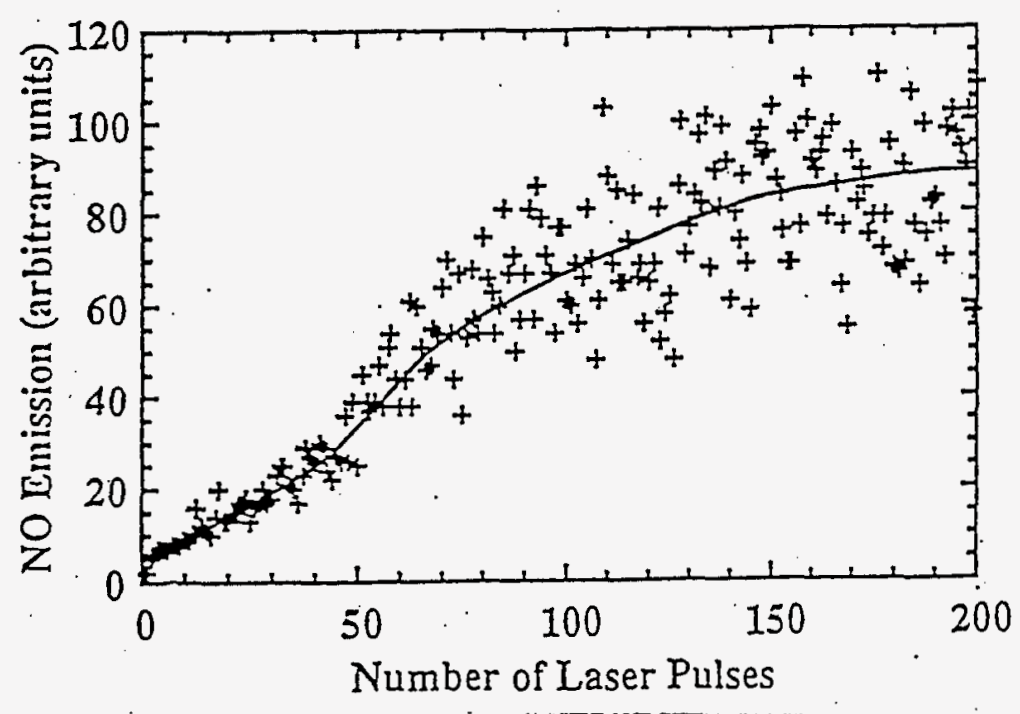

Figure 7. Incubation behavior of crystalline sodium nitrate irradiated with repeated $248 \mathrm{~nm}$ excimer laser pulses. Repeated laser pulses induce increasing neutral NO emission by inducing defects in the sodium nitrate crystal. The laser fluence is $750 \mathrm{~mJ} / \mathrm{cm}^{2}$ per pulse. 
From this data, it is apparent that defects created by NO emission, on more or less perfect $\mathrm{NaNO}_{3}$ surface, strongly enhance subsequent emission. The strong enhancement of $\mathrm{NO}$ emission due to prior laser damage indicate that, under these conditions, emission is largely defect-mediated. At higher laser fluences $(>100 \mathrm{~m}) / \mathrm{cm}^{2}$ on laser-incubated surfaces), other neutral products, primarily $\mathrm{O}_{2}$ and $\mathrm{Na}$, are emitted along with NO. at fluences near $80 \mathrm{~mJ} / \mathrm{cm}^{2}$ on heavily irradiated surfaces, only weak $\mathrm{O}_{2}$ emission is observed. Figure 8 displays the mass spectra produced under increasing laser pulse energy. Above $80 \mathrm{~mJ} / \mathrm{cm}^{2}$ the $\mathrm{NO}$ emission intensity rises sharply along with increasing $\mathrm{O}_{2}$ and $\mathrm{Na}$ emissions; weaker emission at heavier masses are also observed. At these higher fluences, laser induced heating and nonlinear laser-plasma interactions (etching) further enhance the emission intensities resulting in a strong nonlinear dependence on laser fluence.

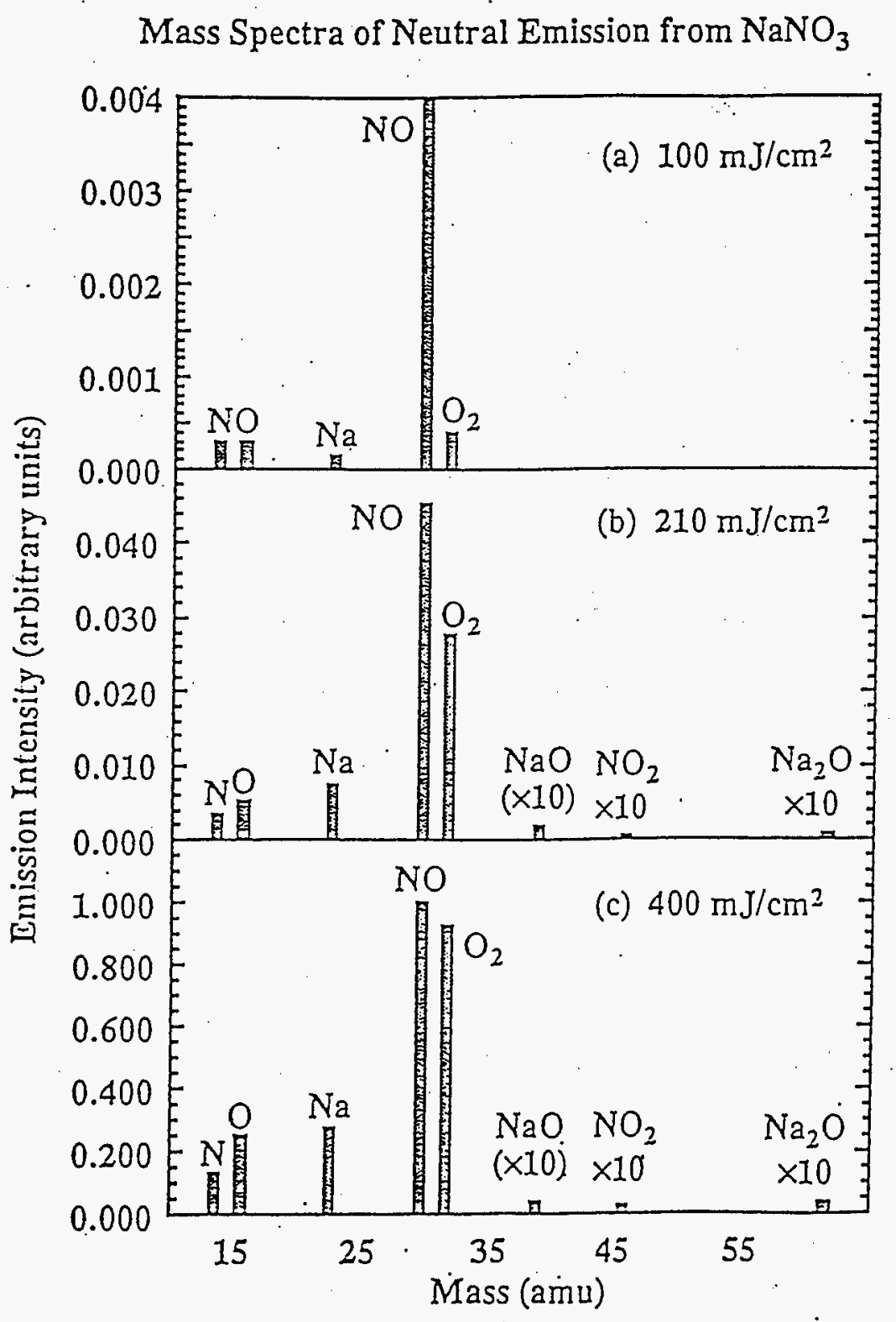

Figure 8. Mass spectra of 248 $\mathrm{nm}$ laser induced emission from $\mathrm{NaNO}_{3}$ irradiated at fluences of
(a) $100 \mathrm{~m} \mathrm{~J} / \mathrm{cm}^{2}$,
(b) $210 \mathrm{~mJ} / \mathrm{cm}^{2}$,
(c) $400 \mathrm{~mJ} / \mathrm{cm}^{2}$ per pulse. 
The neutral emissions produced by 248 -nm radiation share much in common with the neutral emission accompanying bombardment with $1-3 \mathrm{keV}$ electrons. ${ }^{28}$ Both processes yield similar products with similar product velocity distributions. Not surprisingly, defects created by electron irradiation significantly enhance subsequent laser-induced emissions and lower the fluence required for plasma formation. Similar effects have been also observed in other radiological sensitive, wide bandgap materials. We further note that alkali nitrate matrices containing radioactive impurities (such as Hanford-site tank waste) will contain high densities of similar defects which will strongly affect LAMS-based analytical techniques.

\section{Theoretical Studies}

We have used $a b$ initio quantum mechanical methods to calculate the electronic properties of the bulk material, and the clean and defected surfaces of crystalline $\mathrm{NaNO}_{3}$. The results of these calculations provide insight into the photoexcitation/desorption mechanism and support the conclusions drawn from the experimental investigation. Ab initio periodic Hartree-Fock (PHF) calculations indicate that the electronic structure of bulk $\mathrm{NaNO}_{3}$ and the clean cleaved crystal surface are nearly identical, indicating that the absorption profile of the bulk and surface nitrate anions will be the same. Hence, for laser desorption on an undefected sample the photo absorption cross-section is the same for surface and bulk chromophores. This result is consistent with the experimental observation that the NO photodesorption yield (from the clean surface) mimics the bulk absorption profile (i.e. minimal sub-bandgap desorption is observed). ${ }^{3}$ Changes in the excitation spectra are, however, expected to occur when the surface is chemically or structurally defected. Converting $\mathrm{NO}_{3}{ }^{-}$to $\mathrm{NO}_{2}{ }^{-}$ groups on the surface is energetically facile and could possibly occur during experimental sample preparation or irradiation. ${ }^{31}$ The presence of surface $\mathrm{NO}_{2}{ }^{-}$groups is predicted to cause a shift in electron density into the gap region, producing $\mathrm{a}+1 \mathrm{eV}$ to $+2 \mathrm{eV}$ red shift in the surface absorption profile. Such a red shift is inferred in the LAMS experiments from the high NO yield induced by sub-band-gap irradiation energies, for heavily defected surfaces. The molecular-ionic nature of this crystal is evident from the band structure (calculated using PHF). The cationic (sodium) and anionic (nitrate) valence bands are well-separated and flat across the Brillouin zone, with a large gap between the top of the valence and the bottom of the conduction bands. Nitrogen and oxygen orbitals combine to form the "molecular-like" nitrate bands. The uppermost valence bands in the bulk and clean surface are derived predominantly from oxygen $2 p$ orbitals. Photoexcitation of the $\pi^{*} \leftarrow \pi_{2}$ transition is from these states to the 
lowest unoccupied states, which are formed from an equal mixture of oxygen and nitrogen $2 \mathrm{p}$ orbitals.

The "localization" of the $6 \mathrm{eV}$ band on the nitrate ion is due to the "molecular-like" character of crystalline $\mathrm{NaNO}_{3}$. The assignment of this band to the $\pi^{*} \leftarrow \pi_{2}$ transition is based on the spectroscopy of other nitrate compounds (in solids and in solution). 27,32 The "molecular-like" spectroscopic properties of this material have been probed by quantum mechanical CASSCF calculations of the ground and excited state energies of the gas phase species $\left(\mathrm{NO}_{2}^{-}, \mathrm{NO}_{3}^{-}\right.$, and $\left.\mathrm{NO}_{3}\right)$. These high-level ab initio calculations on the isolated gas-phase species reaffirmed the spectroscopic assignment based on earlier molecular orbital calculations. ${ }^{33,34}$ The effect of the crystalline environment on the transition energies was investigated by embedding $\mathrm{NO}_{3}{ }^{-}, \mathrm{NO}_{2}{ }^{-}$and $\mathrm{NO}_{3}$ in a finite array of charges mimicking the first two nearest-neighbor shells in the bulk. All of the states (ground and excited) of the negative ions $\left(\mathrm{NO}_{3}{ }^{-}\right.$and $\left.\mathrm{NO}_{2}{ }^{-}\right)$were equally stabilized by the electrostatic field; thus the transition energies did not change when the ion was placed in the mock crystal field. ${ }^{3}$ In contrast to the negative ions, no stabilization of neutral $\mathrm{NO}_{3}$ occurred when it was embedded in the point charge array. The lack of significant stabilization causes the neutral photodetachment channel to be inaccessible in the $6 \mathrm{eV}$ photoexcitation of the crystal such that the direct dissociation of exited state nitrate $\left(\mathrm{NO}_{3}{ }^{-}\right)^{*}$ to form $\mathrm{NO}+\mathrm{O}_{2}{ }^{-}$is the energetically allowed pathway. The $\mathrm{NO}$ is then ejected from the crystal, leaving $\mathrm{O}_{2}^{-}$trapped (for some time) on the surface. Since the yield of $\mathrm{O}_{2}$ to $\mathrm{NO}$ yield is far less than stoichiometric, the resonant desorption experiments are consistent with the $\mathrm{O}_{2}^{-}$trapping mechanism.

Several conclusion may be drawn from the laser ablation studies of sodium nitrate. It is clear that while it is possible to understand the detailed mechanism involved in NO emission from a pristine sodium nitrate crystal, the emission process itself changes the composition of the crystal surface and therefore the emission mechanism. Any accurate analysis technique based on the NO yield must therefore take into account the condition and exposure history of the sample. Furthermore, the condition of the "matrix" of waste molecules constituting the solid sample can dramatically affect the composition of the ablation plume. Following the detailed studies of solid sodium nitrate we began a series of experiments on other known waste compounds singularly and in combination with sodium nitrate. In the latter case, $\mathrm{NaNO}_{3}$ may be considered the matrix for laser ablation. Figure 9 displays the mass spectra obtained following laser ablation of $\mathrm{Na}_{3} \mathrm{PO}_{4}$ embedded in an excess of sodium nitrate. The dominant peak is atomic 
phosphor with less intense features at the $\mathrm{PO}, \mathrm{PO}_{2}, \mathrm{PO}_{3}$, and $\mathrm{PO}_{4}$ masses. The ablation wavelength $(213 \mathrm{~nm})$ is efficiently absorbed by both the nitrate and phosphate chromophores leading to fragmentation of these species. Similar results are obtained for the analogous sulfate salts. It is also apparent that LAMS of phosphate and sulfate salts produce highly fragmented mass spectra and only weak parent ion signals. This is in sharp contrast to the strong parent molecular ions observed in MALDI mass spectrometry of these oxyanions. It is clear that sodium nitrate is not a "good matrix" material and that use of far UV wavelength leads to fragmentation.

\section{Sodium Phosphate}

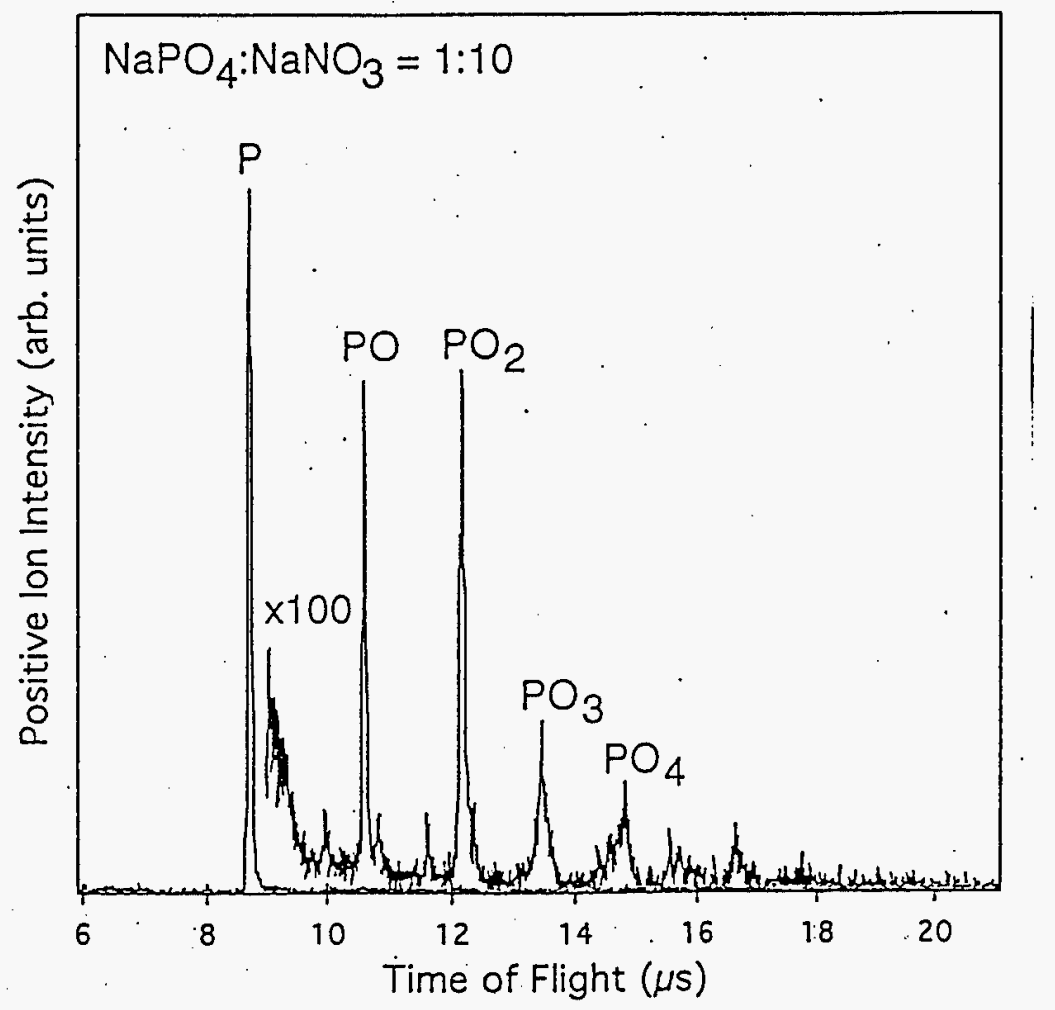

Figure 9. Laser ablation mass spectra phosphate salts. While only a weak parent mass peak is observed, the fragmentation pattern itself is characteristic of the presence of phosphate.

B) Development of Diode-Laser-Based Excitation Schemes for CW Resonance Ionization of Technitium

Solid state diode laser technology has undergone rapid development in recent years due to their immense commercial impact. As a consequence of this development, device reliability, power, wavelength range and tunablilty have improved dramatically. Diode lasers are now frequently used in atomic and molecular spectroscopic applications. ${ }^{35}$ The emission characteristics of room temperature diode lasers, although often suitable for such spectroscopic applications, can in general be improved from the "naked" diode laser configuration by using an external cavity to provide selective 
feedback. We have developed one of the simpler selective feedback configurations, the Littrow grating cavity, as a reliable and optimized source for analytical spectroscopy applications. The following results were obtained using a sharp LTO-015 diode laser nominally operating at $834 \mathrm{~nm}$ : Any desired wavelength in the region $818-848 \mathrm{~nm}$ can be reached by coarse tuning of the grating angle and minor $(<1 \%)$ adjustments of injection current. Linewidth $<3 \mathrm{MHz}$ (probably $<1 \mathrm{MHz}$ but current measurements are limited by available interferometer resolution) have been achieved without observable $(>0.05 \%)$ side modes. Continuous, single-frequency tuning of $8-10 \mathrm{GHz}$ is possible using piezoelectric scanning of the external cavity length. Output power up to 12 milliwatts is readily obtained, however, for longevity and stability, typical output power is limited to $8 \mathrm{~mW}$. It should be noted that continuous scanning regions greater than the observed 8-10 GHz can be achieved either by synchronously scanning injection current with external cavity length or by using specially prepared diode lasers with antireflection coated output facets.

\section{Optimal Laser Ionization Schemes}

A large number of three-step laser excitation schemes for selective ionization of technetium have been investigated at the University of Mainz. However, all of those methods have used only the wavelengths that are generated by copper-vapor-laser pumped dye lasers. Unfortunately, the lowest lying allowed transitions are in the violet and ultra-violet regions of the spectrum and thus it was necessary to frequency-double for the first step. In all cases, the excitation was from the $4 \mathrm{~d}^{5} 5 \mathrm{~s}^{2}{ }^{6} \mathrm{~S}_{5 / 2}$ ground state to various components of the $4 \mathrm{~d}^{6} 5 \mathrm{p}$ configuration between 313 and $318 \mathrm{~nm}$. While this is in the best range for the available frequency-doubled dye laser wavelengths, it is not optimal in terms of atomic spectroscopy since it involves relatively weak intercombination (two-electron excitation) transitions. The second step excitations were generally of a one-electron nature, for the most part into various fine structure components of the $4 \mathrm{~d}^{6} 6 \mathrm{~s}$ ( $\left.{ }^{6} \mathrm{D}_{\mathrm{J}}\right\}$ configuration using wavelengths between 787 and 821 $\mathrm{nm}$. The final ionization step then used excitation to various unassigned autoionizing. levels using wavelengths between 650 and $850 \mathrm{~nm}$.

It should be possible to improve considerably on the excitation schemes described above using the output of frequency doubled diode lasers. Several general principles have been used to select a more optimal excitation scheme. These include: 1) Only allowed, one-electron transitions should be used. 2) Choose $\Delta \mathrm{J}=\Delta \mathrm{L}=+1$ for all transitions in order to maximize transition probabilities. 3) If possible, ladder excitation should begin with the bluest (most energetic) photon and progress to lower energy 
photons in the subsequent steps, because increased laser power is generally required to saturate the subsequent steps. Allowed transitions out of the ground state can usually be saturated with approximately $1 \mathrm{~mW}$ laser power ( $1 \mathrm{~mm}$ diameter beam) while saturation of excitation to Rydberg states requires several hundred milliwatts. Limiting the intensity of energetic photons in this manner minimizes background from nonresonant multiphoton processes. 4) The final step should involve photoionization of a Rydberg state atom using a continuous wave (CW) carbon dioxide laser. This is actually an extension of (3) and prior work at PNNL has shown that this can lead to CW saturation of the ionization step, even in the absence of autoionizing resonances, without significant production of background. These criteria lead directly to the schemes detailed in Figure 10. In the case of technitium, the excitation steps are: $4 \mathrm{~d}^{5} 5 \mathrm{~s}^{2}$ ${ }^{6} \mathrm{~S}_{5 / 2}$ (ground state) $429.82 \mathrm{~nm}$ to $4 \mathrm{~d}^{5} 5 \mathrm{~s} 5 \mathrm{p}{ }^{6} \mathrm{P}_{7 / 2}\left(23265.33 \mathrm{~cm}^{-1}\right), 461.81 \mathrm{~nm}$ to $4 \mathrm{~d}^{5} 5 \mathrm{~s} 5 \mathrm{~d}$ ${ }^{6} \mathrm{D}_{9 / 2}\left(44919.07 \mathrm{~cm}^{-1}\right), 741-764 \mathrm{~nm}$ to $4 \mathrm{~d}^{5} 5 \mathrm{snf}{ }^{6} \mathrm{~F}_{11 / 2}\left(58000-58400 \mathrm{~cm}^{-1}, \mathrm{n}=14\right.$ to 20) and $10.6 \mu \mathrm{m}$ ionization step. It is worthwhile to note, particularly for routine analytical measurements, that the three resonance steps may be performed with diode lasers. The first two steps require frequency doubling of the diode lasers into the blue region of the optical spectrum.

\section{Diode Laser Excitation Schemes}

Calcium

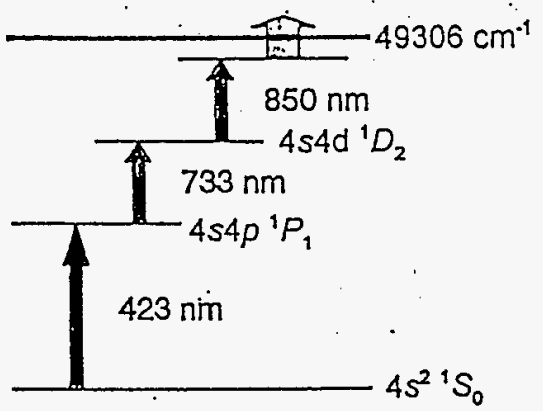

Plutonium

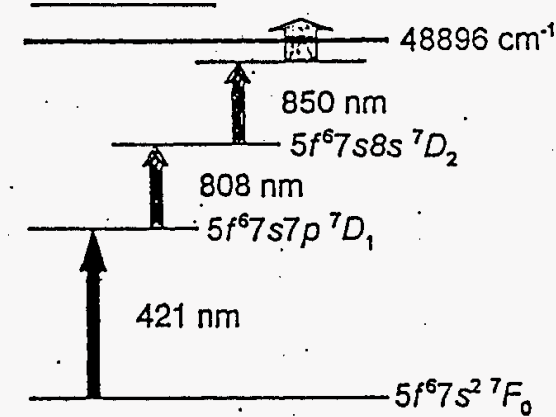

Strontium

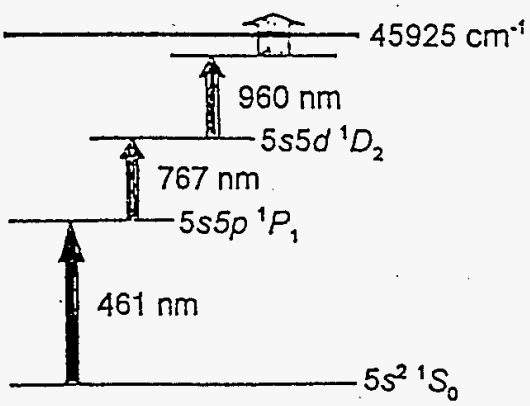

Technetium

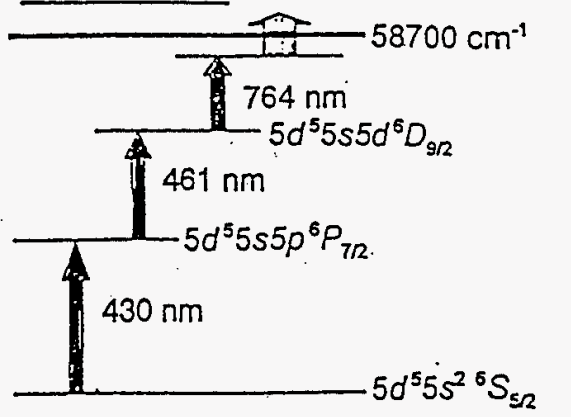

10) Schematic of optimized $\mathrm{cw}$ laser ionization schemes for technitium, strontium, plutonium, and calcium. 


\section{Frequency Doubling the External Cavity Diode Laser}

Extending the operation of diode lasers into the blue region is essential for a wider range of applications. Only a limited number of elements, including heavier alkali metals, some lanthanides, and actinides have strong resonance transitions that are accessible to the normal red and near infrared operating regions of diode lasers. Many more elements have strong transitions in the spectral region which could be covered by frequency doubled diode lasers. Of particular interest here are the resonance lines of technetium and strontium at 428 and $461 \mathrm{~nm}$, respectively. These wavelengths can be reached with the relatively inexpensive and relatively powerful diodes operating between 840 and $925 \mathrm{~nm}$ and using potassium niobate as the frequency doubling medium. Fortunately, potassium niobate has very high nonlinear coefficients and can be non critically phase matched for these wavelengths by temperature tuning. Both are important for obtaining efficient doubling of lasers with only tens of milliwatts of continuous power in the fundamental beam.

The efficient frequency doubling of diode lasers has been achieved and is a major accomplishment of our SERDP effort. A CW diode laser operating at $846 \mathrm{~nm}$ with an output power of $7 \mathrm{~mW}$ has been frequency doubled to a blue wavelength of $423 \mathrm{~nm}$ using a temperature tuned potassium niobate crystal in an external ring enhancement cavity. Figure 11 displays the schematic design of the external ring cavity. With the design used, frequency doubling efficiencies of approximately $15 \%$ are reached routinely and reliably.

\section{Frequency-doubling}

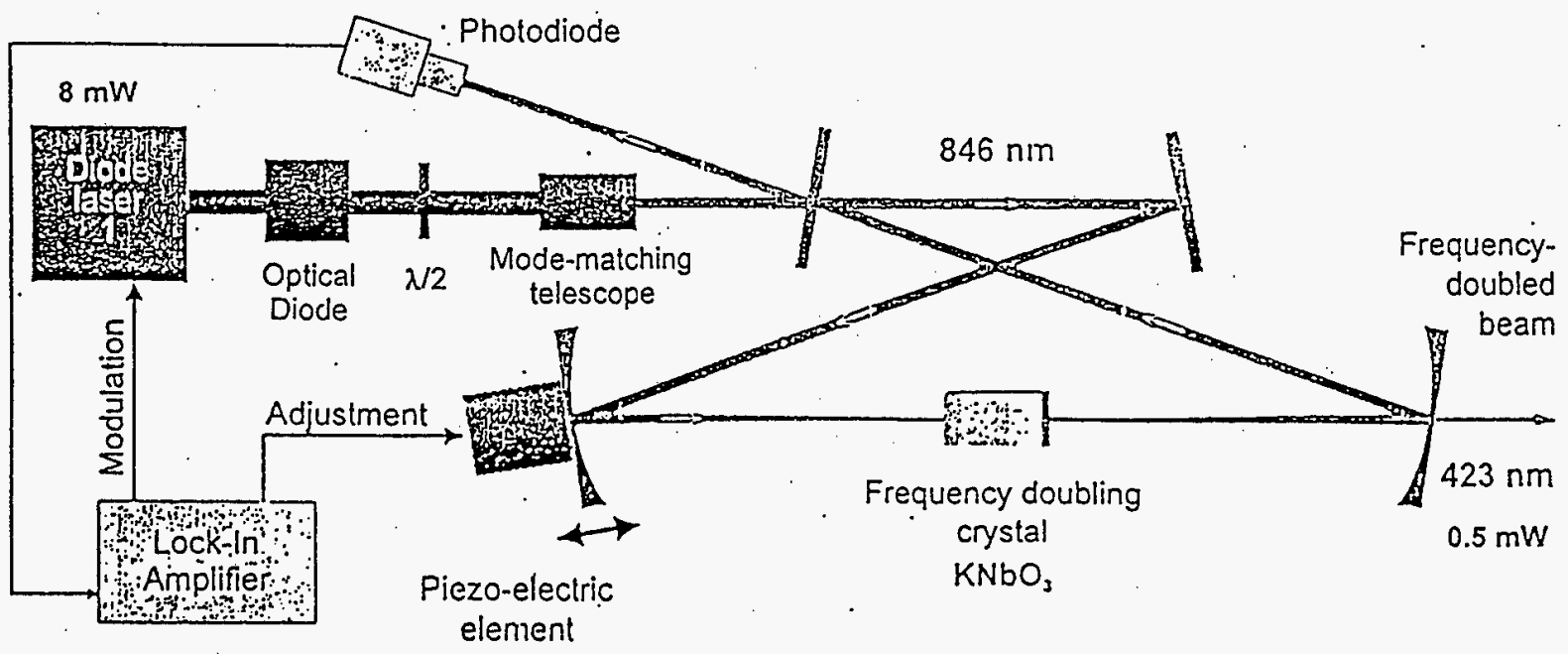

11) Schematic design of the external ring cavity used for efficient frequency doubling of $\sim 840 \mathrm{~nm}$ room temperature diode laser. Doubling efficiencies of $15 \%$ are routinely
achieved. 
After losses from Brewster windows and ring output coupler mirror, usable $423 \mathrm{~nm}$ power is typically 700 microwatts. This power is generally sufficient to saturate Doppler-free allowed atomic resonance transitions that are used as the first step in multiple-resonance RIMS studies. However, with available, more powerful diode lasers it should be easily possible to scale the frequency doubled output powers into the 10 $\mathrm{mW}$ range, if needed. With available diode lasers and the temperature tuning range of potassium niobate it is possible to generate wavelengths between 415 and $470 \mathrm{~nm}$. Species of interest relevant to nuclear waste problems that can be addressed by these wavelengths include Tc-99 (430 nm), Sr-90 (461 nm), Cs-135,137 (455 nm), Plutonium $(421 \mathrm{~nm})$, and Uranium (426) $\mathrm{nm}$.

\section{Locking to Atomic Reference Signals}

Stabilizing the frequency of high resolution CW lasers is necessary for reliable analytical measurements. For reproducible measurements the frequency must be held constant to within a small fraction of the natural atomic linewidth over periods of several hours. The frequency of the external cavity diode laser has been locked to an atomic reference signal. Three different types of measurements were used and evaluated for locking the laser frequency. These included normal absorption, saturated absorption, and optogalvanic spectroscopy. In all cases, the detected signal (photodiode detection of transmitted laser intensity for absorption measurements, and change in hollow cathode discharge impedance for optogalvanic measurements) was analyzed with a lock-in amplifier, which produces a derivative signal suitable for feedback and driving the laser frequency to the center of the absorption line. All three approaches were found to provide suitable results: It was possible to lock the laser to the atomic line center for periods up to 60 hours ( 2 days typical) when working with the diode laser fundamental frequency, demonstrating the type of long term stability that is mandatory for routine analytical measurements. In similar experiments, the above described frequency doubled diode laser has been locked to the Doppler free resonance line of Ca-40 in a small (2-3/4" conflat cross) atomic beam apparatus. Residual frequency modulation of $\sim 2 \mathrm{MHz}$, which results from locking of the doubling ring cavity, is detected in absorption by the atomic beam with a lock-in amplifier. This results in a derivative signal suitable for feedback to the laser frequency control, holding the laser frequency on the center of the atomic absorption. This method has successfully locked the laser frequency to the atomic transition for periods of up to eight hours, limited by long term thermal drift of the ring doubling cavity. It is expected that with the use of temperature stabilization or improved materials that stable frequency locking, of several days duration, can be achieved. 


\section{Frequency Shifting}

Frequency locking to an atomic absorption can be performed realistically only for high abundance, naturally occurring isotopes, as is the case for Ca-40. Then, measurement of rare isotopes requires shifting of the laser frequency corresponding to the optical isotope shifts. For isotope shifts up to $\sim 1 \mathrm{GHz}$ this can be done easily and reliably with acousto-optic modulators. We have demonstrated frequency shifting of the doubled diode laser over the range of $135-175 \mathrm{MHz}$ (appropriate to the measurement of the longlived radioisotope $\mathrm{Ca}-41$ ) with $85 \%$ efficiency in the 1st order Bragg diffraction. The remaining undiffracted (0th order), which is not frequency shifted, is then used for locking to the reference atomic absorption. This method provides a relatively simple and absolute frequency locking scheme. However, there are cases where no stable reference isotopes are available, e.g., technetium and plutonium. Here, fringe offset locking techniques with a Zeemann stabilized He:Ne laser, as has been previously developed and used at PNNL, can be used to achieve comparable laser frequency stabilization.

The development of optimal laser ionization schemes followed by the technological advances of external cavity control, ring cavity frequency doubling, and locking and shifting of the diode laser output, provide the necessary technical tools for routine utrasensitive detection of technetium, strontium, and other elements. The reliability of solid state diode lasers makes them the tool of choice for such analysis. These results indicate that an applied engineering effort to design and build an ultrasensitive analytical apparatus, that is based on solid state diode lasers, is worth strong consideration.

\section{CONCLUSIONS}

The Laser Ablation/Ionization Characterization of Solids Program has succeeded in achieving many goals including the molecular speciation of a variety of known waste compounds and combinations of compounds and the development of excitation schemes and diode laser technology for ultrasensitive detection of radioisotopes. The early laser ablation studies characterized the important processes for analysis of high salt content waste and exposed the limitations of the LAMS technique for certain classes of waste samples. This knowledge, in turn, led to the exploration of matrix assisted laser desorption ionization and the speciation of important waste compounds and combinations of waste compounds. The results of the MALDI studies are extremely 
encouraging and indicate that an entire class of chelating agents, their degradation products, organic acids, and several oxyanions are amenable to rapid molecular analysis.

We have recently refocussed the direction of the fundamental laser ablation studies toward laser desorption of calcite; a particularly stable form of calcium carbonate found in tank waste and in the earth's subsurface. We believe that LAMS studies of this material will provide much fundamental data, and will guide the soil/waste analysis work in much the same way that the sodium nitrate studies guided the tank waste investigations. We will continue to apply MALDI, in the positive and negative mass modes, to analysis of waste compounds, alone and in combination to simulate waste.

To date, all of the necessary technical tools for routine utrasensitive detection of technitium, strontium, and other radioisotopes using solid state diode lasers have been developed. In particular, SERDP funding has supported research into the external cavity control of diode lasers, laser frequency doubling using an external ring cavity, and the locking of the diode laser to an atomic resonance. Each of these individual accomplishments represents a significant advance. In addition, specific excitation schemes based on diode laser emission have been designed for technitium, strontium, plutonium, and calcium. The schemes for detection of strontium and calcium have recently been demonstrated. ${ }^{12,36,37}$ It should be stressed that the compact diode laser quite likely represents the most reliable technology available for field analysis and that an applied engineering effort to design such a device should be considered.

A major goal of this SERDP program is to communicate these results to more applied analytical programs such that this fundamental knowledge can guide the approach and design of field analysis. This report is an important step toward achieving this goal. The Appendices contain a listing of the refereed publications that resulted from SERDP funding of Laser Ablation/Ionization Characterization of Solids, a partial listing of public presentations and a highlighting of the relevance of this program to DoD.

Acknowledgment: This research was supported by the Strategic Environmental Research and Development Program. Pacific Northwest National Laboratory is operated for the U.S. Department of Energy by Battelle under contract No. DE-AC06-76RLO 1830. Computer resource allocations at the National Energy Research Supercomputer Center (Livermore, CA) were provided by the Scientific Computing Staff, Office of Energy Research Division of Chemical Sciences, Office of Basic Energy Sciences. 


\section{References}

1. E. Schroeder, H. Muenster, A. Overberg and I. Merfort. MALDI-TOF and Electrospray Ionization Mass Spectrometry Applied to the Analysis of Flavonold Glucosides from Arnica Plant Extracts 1-939 (Chicago, IL, 1994).

2. R.B. Lucke, J.A. Campbell, K.L. McKeeta and S.A. Clauss. Analysis of Chelators and Chelator Fragments in Mixed Hazardous Wastes by Derviatization GC/MS (Nashville, Tennessee, 1991).

3. M.I. McCarthy, K.I. Peterson and W.P. Hess, J. Phys. Chem. 100, (1996).

4. K. Tang, S.L. Allman, R.B. Jones and C.H. Chen, Anal. Chem. 65, 2164 (1993).

5. K. Strupat, M. Karas and F. Hillenkamp, Intl. J. Mass Spec. Ion Processes 111, 89 (1991).

6. R.C. Beavis and J.N. Bridson, J. Phys. D: Appl. Phys. 26, 442 (1993).

7. K. Dreisewerd, M. Schurenberg, M. Karas and F. Hillenkamp, Intl. J. Mass Spectrom. Ion Processes 154, 171 (1996).

8. A.M. Belu, J.M. DeSimone, R.W. Linton, G.W. Lange and R.M. Friedman, J. Am. Soc. Mass Spectrom. 7, 11 (1996).

9. L. Pasa-Tolic, Y. Huang, S. Guan, Y.S. Kim and A.G. Marshall, J. Mass Spectrom. 30, 825 (1995).

10. J.A. Campbell, S.M. Stromatt, D.W. Koppenaal, R.M. Bean, T.E. Jones, D.M. Strachan and H. Babad, Anal. Chem. 66, (1994).

11. J.A. Campbell, R.B. Lucke and S.A. Clauss. Application of LC/MS to the Study of Chelators in Mixed Hazardous Wastes 1-1334 (Nashville, Tennessee, 1991).

12. H.J. Kluge, B.A. Bushaw, G. Passler, K. Wendt and N. Trautman, J. Anal. Chem. 350, (1994).

13. K. Knutsen and T.M. Orlando, Phys Rev. Lett. (submitted) (1996).

14. S. Jespersen, W.M.A. Niessen, T.U. R. and J. van der Greef, J. Mass Spectom. 30, 357 (1995).

15. O. Kornienko, S. Brynjelsen, L. Hanley and T.M. Orlando. Analysi of EDTA by laser desorption ion trap mass spectrometry (Portland, OR, 1996).

16. A.I. Gusev, W.R. Wilkinson, A. Proctor and D.M. Hercules, Anal. Chem. 67, 1034 (1995).

17. H. Ehring, M. Karas and F. Hillenkamp, Organic Mass Spectrometry 27, 472 (1992).

18. S.L. Cohen and B.T. Chait, Anal. Chem. 68, 31 (1996).

19. P.C. Liao and J. Allison, J. Mass Spec. 30, 408 (1995).

20. J.A. Campbell, K.L. Wahl, K.E. Grant, S.A. Clauss, G.M. Mong, R.B. Lucke and B.D.

Lerner. DOE Methods for Evaluating Environmental and Waste Management Samples (1995).

21. R.E. Johnson, Intl. J. Mass Spec. Ion Processes 139, 25 (1994). 
22. M. Karas, A. Ingendoh, U. Bahr and F. Hillenkamp, Biomed. Environ. Mass Spectrom. 18, 841 (1989).

23. J.A. Campbell, H.R. Udseth and R.B. Lucke. Application of Electrospray Mass Spectrometry to the Analysis of Chelator and Chelator Fragments in Mixed. Hazardous Wastes 1-1334 (Washington D.C., 1992).

24. J.A. Campbell, S.A. Clauss, K.E. Grant, V. Hoopes, B.D. Lerner, R.B. Lucke, G.M. Mong, J. Rau and R. Steele. Flammable Gas Safety Program, Analyical Methods Development: FY 1993 Progress Report (Pacific Northwest Laboratory, Richland, Washington., 1993).

25. K.L. Busch, J. Mass Spectrom. 30, 233 (1995).

26. R.J. Levis, Annual Reviews Inc. (1994).

27. H. Yamashita, J. Phys. Soc. 33, (1972).

28. J.J. Shin, S.C. Langford, J.T. Dickinson and Y. Wu, Nucl. Instrum. Meth. Phys. Rev. B 103, (1995).

29. R.A. Bradley, E. Lanzendorf, M.I. McCarthy, T.M. Orlando and W.P. Hess, J. Phys. Chem. 99, 11715 (1995).

30. R. Webb, J.T. Dickinson and S.C. Langford, Nucl. Instrum. Meth. Phys. Rev. B 103, (1995).

31. R.C. Plumb and J.O. Edwards, J. Phys. Chem. 96, (1992).

32. H. Yamashita and R. Kato, J. Phys. Soc. 29, (1970).

33. L. McEwen, J. Chem. Phys. 34, (1961).

34. L.E. Harris, J. Chem. Phys. 58, (1973).

35. C.E. Weiman and L. Hollberg, Rev. Sci. Instrum. 62, (1991).

36. K. Zimmer, Appl. Phys. B 59, (1994).

37. B.A. Bushaw, H.J. Kluge, J. Lantzsch, R. Schwalbach, J. Stenner, H. Stevens, K. Wendt and K. Zimmer, Z. Phys. D 28, (1993). 
Appendix: List of publications and presentations resulting from SERDP supported work.

\section{Publications}

R. A. Bradley, Jr., E. Lanzendorf, M. I. McCarthy, K. Peterson, T. M. Orlando, and W. P. Hess. "Molecular NO Desorption From Crystalline Sodium Nitrate by Resonant Excitation of the $\pi-\pi^{*}$ Transition." J. Phys. Chem. 99, 11715, (1995).

W. P. Hess, B. A. Bushaw, M. I. McCarthy, J. A. Campbell, S. D. Colson, and J. T. Dickinson, "Laser Ablation/Ionization Characterization of Solids: Interim Progress Report of the Strategic Environmental Research Development Program." (January, 1996)

Wayne P. Hess, Kristine A. H. German, Richard A. Bradley, and Maureen I. McCarthy. "Laser Ablation of Sodium Nitrate: NO Desorption Following Excitation of the $\pi-\pi^{*}$ Band of the Nitrate Anion." Appl. Surf. Sci. 96-98, 321 (1996).

M. I. McCarthy, K. Peterson, and W. P. Hess. "Electronic Structure of Sodium Nitrate: Investigations of Laser Desorption Mechanisms." J. Phys. Chem. 100, 6708, (1996).

Kenneth M. Beck, Kristine A. H. German, and Wayne P. Hess, "Thermal Distributions Deduced from $(2+1)$ Resonance Enhanced Multiphoton Ionization of CO Products." Chem. Phys. Lett. 256, 297, (1996).

Kenneth M. Beck, David P. Taylor, and Wayne P. Hess, "Photostimulated Desorption of CO from Geologic Calcite Following 193 nm Irradiation." Phys. Rev. B. (submitted). .

Steven C. Goheen, Karen L. Wahl, Wayne P. Hess, and James A. Campbell, "Mass Spectrometry of Low Molecular Weight Solids by Matrix Assisted Laser Desorption Ionization." J. Mass Spectrom. (submitted).

David P. Taylor, Wayne P. Hess, and M.I. McCarthy, "The Structure of Water on the $\mathrm{NaCl}$ (100) Surface." J. Phys. Chem. (in prep).

R. Webb, J. T. Dickinson, and S. C. Langford, "Neutral Atom and Molecule Emission Accompanying 248-nm Laser Irradiation of Single Crystal $\mathrm{NaNO}_{3}$."Nucl. Instrum. Meth. Phys. Rev. B . 103, 297, (1995).

J.-J. Shin, S.C. Langford, J. T. Dickinson, and Y. Wu "Electron Stimulated Neutral and Ion Emission from Single Crystal $\mathrm{NaNO}_{3}$."Nucl. Instrum. Meth. Phys. Rev. B . 103, 284, (1995).

J. T. Dickinson, J.-J. Shin, and S.C. Langford, "Laser Induced Emission of Neutral Atoms and Molecules from Electron Irradiated $\mathrm{NaNO}_{3}$." Appl. Surf. Sci. 96-98, 326 (1996). 
B. A. Bushaw, H.-J. Kluge, J. Lantzsch, R. Schwalbach, J. Stenner, H. Stevens, K. Wendt, and K. Zimmer, "Hyperfine Structure in $5 s 4 d{ }^{3} \mathrm{D}-5 \mathrm{snf}$ Transitions of ${ }^{87} \mathrm{Sr}$." Z. Phys. D 28, 275-281 (1993).

K. Zimmer, J. Stenner, H.-J. Kluge, J. Lantzsch, L. Monz, E.W. Otten, G. Passler, R. Schwalbach, M. Schwarz, H. Stevens, K. Wendt, G. Herrmann, S. Niess, N. Trautmann, K. Walter, and B. A. Bushaw, "Determination of ${ }^{90} \mathrm{Sr}$ in Environmental Samples with Resonance Ionization Spectroscopy in Collinear Geometry," Appl. Phys. B 59, 117-121 (1994)

H.-J. Kluge, B. A. Bushaw, G. Passler, K. Wendt, N. Trautmann, "Resonance ionization spectroscopy for trace analysis and fundamental research," Fresenius J. Anal. Chem. 350, 323-329 (1994).

J. Lantzsch, B. A. Bushaw, G. Herrmann, H.-J. Kluge, L. Monz, S. Niess, E. W. Otten, R. Schwalbach, M. Schwarz, J. Stenner, N. Trautmann, K. Walter, K. Wendt, K. Zimmer, "Trace analysis of the Radionuclides ${ }^{90} \mathrm{Sr}$ and ${ }^{89} \mathrm{Sr}$ in environmental samples I: Laser Mass Spectrometry," Angew. Chem. Int. Ed. Engl. 34, 181-183 (1995).

J. Lantzsch, B. A. Bushaw, V. A. Bystrow, G. Herrmann, H.-J. Kluge, S. Niess, E. W. Otten, G. Passler, R. Schwalbach, M. Schwarz, J. Stenner, N. Trautmann, K. Wendt, Y. V. Yushkevich, K. Zimmer, "Trace determination of ${ }^{90} \mathrm{Sr}$ and ${ }^{89} \mathrm{Sr}$ in environmental samples by collinear resonance ionization spectroscopy," AIP Conf. Ser. 329 (RIS 94), H.J. Kluge, J. E. Parks, K. Wendt, Eds., 251-254 (1995).

B. A. Bushaw, H.-J. Kluge, J. Lantzsch, R. Schwalbach, M. Schwarz, J. Stenner, H. Stevens, K. Wendt, K. Zimmer, "Hyperfine structure of ${ }^{87.89} \mathrm{Sr} 4 \mathrm{~s} 4 \mathrm{~d}^{3} \mathrm{D}-5 \mathrm{snf}$ transtions in collinear fast beam RIMS," AIP Conf. Ser. 329 (RIS 94), H.-J. Kluge, J. E. Parks, K. Wendt, Eds., 381-384 (1995).

J.-J. Shin, and S.C. Langford, and J. T. Dickinson, "Interaction of wide band gap single crystals with $248 \mathrm{~nm}$ excimer radiation $\mathrm{V}$. The role of electron beam damage in the positive ion emisson from $\mathrm{NaNO}_{3}$. (Submitted to J. Appl. Phys.)

R. L. Webb, J. T. Dickinson, and G. J. Exarhos, "Characterization of particle accompanying laser ablation of $\mathrm{NaNO}_{3}$." (Submitted to Applied Spectroscopy)

R. L. Webb, S. C. Langford, and J. T. Dickinson, "The role of defects in the rear side ablation of $\mathrm{MgO}$ at $308 \mathrm{~nm}$." (J. Appl. Phys. in press)

D. R. Ermer S. C. Langford, J. T. Dickinson, "'Interaction of wide band gap single crystals with $248 \mathrm{~nm}$ excimer radiation IV Mg+ emission from MgO." (Submitted to J. Appl. Phys.)

S. C. Langford and J. T. Dickinson, "Applications and Mechanisms of Laser Ablation for Elemental Analysis of nuclear Wastes and Contaminated Soils." SPIE Manuscript 283520 p.1. 1996, SPIE Meeting Denver, CO. 


\section{Selected Presentations}

IEEE/LEOS 1996 Summer Topical Meetings, Keystone, CO August 5-9, 1996, "Laser Desorption of NO and CO from Sodium Nitrate and Calcium Carbonate Crystals." Presented by W. P. Hess.

Gordon Research Conference on Laser Interacions with Materials, Holderness, New Hampshire, June 9-14, 1996. Molecular Desorption from Ionic Molecular Crystals Following Resonant UV Excitation." Presented by W. P. Hess.

"Laser Ablation of Sodium Nitrate in the $6 \mathrm{eV}$ Band." Physical Chemistry Seminar, Weizmann Institute of Science, Rehovot, Israell, June 1994. Presented by W. P. Hess.

"Laser Ablation of Sodium Nitrate in the $6 \mathrm{eV}$ Band." Physical Chemistry Seminar, Hebrew University, Jerusalem, Israel, June 1994. Presented by W. P. Hess.

"Laser Interactions with an Ionic Molecular Crystal : Sodium Nitrate Ablation in the 6 eV Valence Band." Gordon Conference on Laser Surface Interactions, Colby-Sawyer College, New London, New Hampshire, August, 1994. Presented by W. P. Hess.

"Surface Photochemistry without an Adsorbate or Laser Desorption of Sodium Nitrate in the $6 \mathrm{eV}$ Band." Western Spectroscopy Association Conference, Asilomar Conference Center, Pacific Grove, California, February 1995. Presented by W. P. Hess.

"Laser Ablation/Ionization Characterization of Solids." Strategic Environmetal Research Development Program Symposium, Washington D.C., April, 1995. Presented by W.P. Hess.

"Laser Ablation of Sodium Nitrate: NO Desorption Following Excitation of the $\pi-\pi^{*}$ Band of the Nitrate Anion." European Materials Research Society Spring Meeting, Symposium F, Conference on Laser Ablation, Strasbourg, France May, 1995. Presented by W.P. Hess.

"Molecular NO Desorption from Sodium Nitrate by Resonant Excitation of a $\pi-\pi^{*}$ transition on $\mathrm{NO}_{3}$ Anion." American Chemical Society Regional Meeting, Park City, Utah, June, 1995. Presented by W. P. Hess.

"Laser ionization Probing of Molecular Product State Distributions: Photodissociation of Isolated Molecules and Photdesorption from Ionic Crystals." Physiscs Deparment Coloquium, Washington State University, Pullman, Washington, Spetember 1995. Presented by W. P. Hess.

"Laser Desorption from Resonant Excitation of Molecular Ionic Crystals." Chemistry Deparment Coloquium, Colorado State University, Fort Collins, Colorado, Spetember 1995. Presented by W. P. Hess. 
"Laser Desorption from Resonant Excitation of Molecular Ionic Crystals." Chemical Physics Coloquium, University of Colorado, Boulder Colorado, September 1995. Presented by W. P. Hess.

"Matrix-Assisted Laser Desorption Ionization-TOF of Low Molecular Weight Organics." American Society of Mass Spectrometry Meeting, Portland, Oregon, May 1996. Presented by J.A. Campbell.

"Excimer Laser Interactions with Wide Bandgap Materials," Freie Universitat, Berlin, Germany, June, 1994. Presented by J. T. Dickinson.

"Laser Desorption and Ablation of Wide Bandgap Materials," Gordon Conference on Laser-Materials Interactions, August, 1994. Presented by J. T. Dickinson.

"Laser Desorption of Ions and Neutrals from Ionic Crystals," Physics Department, U. of Osaka, Osaka, Japan, January 1995. Presented by J. T. Dickinson.

"Excimer laser interactions with single crystal NaNO3," American Vacuum Society PNW Meeting, Portland, September, 1994. Presented by J. T. Dickinson.

"Laser Induced Positive Ion Emission and Laser Ablation from single crystal NaNO3," American Vacuum Society PNW Meeting, Portland, September, 1994. Presented by J. T. Dickinson.

"The role of defects in the laser induced decomposition of NaNO3," Conference on Laser Ablation, Strasbourg, France, May, 1995. Presented by J. T. Dickinson.

"Applications and Mechanisms of laser ablation for elemental analysis of nuclear wastes and contaminated soil," MRS Fall Meeting, Boston, Nov. 1995. Presented by J. T. Dickinson.

"Strontium 90 detection by collinear beam spectroscopy", University of Bern, Bern, Switzerland, June 28, 1993. Presented by B. A. Bushaw.

"Perturbed Hyperfine Structure in $5 s 4 d{ }^{3} D-5 s n f$ Transitions of ${ }^{87} \mathrm{Sr}$," 25 th annual conference of the European Group for Atomic Spectroscopy, Caen, France, July 13, 1993. Presented by B. A. Bushaw.

"Rare Isotope Analysis with cw-RMMS", Gesellschaft fuer Schwerionforschung (GSI), Darmstadt, Germany, Oct. 20, 1993. Presented by B. A. Bushaw. 
Appendix B: Relevance to the Department of Defense

The Laser Ablation/Ionization Characterization of Solids program has been funded under the compliance pillar of the SERDP program. While many application of our SERDP efforts directly impact DOE hazardous and mixed waste clean-up it was agreed at the SERDP In Process Review (May, 1996), that this report should comment upon program relevance to DoD to encourage greater mission connection and promote follow-on funding. As suggested by Dr. John Harrison, Dr. Wayne Hess contacted Dr. John Cullinane of the US Army Waterways Experiment Station: A summary of program results and reports have been sent to Dr. Cullinane and Dr. Cullinane has agreed to distribute these reports to the appropriate technical contacts to increase visibility of the Laser Ablation/Ionization Characterization of Solids program to possible DoD end users.

There are distinct scenarios for the application of Laser Ablation/Ionization Characterization technology. The most obvious scenario involves monitoring environmental cleanup in friendly areas. Direct reductions of expense and task completion time result when the cleanup contractor knows the identity and quantity of materials to be removed. The DoD has an extensive list of such contaminated sites which will require methods for determining end state cleanliness. Examples of contamination includes spills of hydrocarbons, polychlorinated biphenyls and other carcinogens, lead, and mercury. Soil contamination at firing range sites may require, in excess of removal of unexploded ordinance, soil analysis, again to verify a clean end state. Numerous contaminated DoD sites such as the Rocky Mountain Arsenal, could likely make use of a field deployable analytical instrument based on the techniques developed in this program.

A second scenario involves monitoring unfriendlies for chemical weapons (CW) and nuclear proliferation (NP). We have submitted proposals for the development of a compact, rugged, field-deployable analytical systems for environmental monitoring. Such a system could provide rapid detection of chemical agents under battlefield conditions. The sensitivity to solid species could verify chemical agent use via detection of even minor soil contamination long after the fact. The development of diode laser technology has been rapid in recent years due to their immense commercial impact. As a consequence of this development, device reliability, power, wavelength range and tunablilty have improved dramatically. Efforts under the Laser Ablation/Ionization Characterization of Solids program indicate that a device capable of extreme sensitivity (femtogram level) for techetium or other fission products could be constructed. While this report has described the environmental impact of technetium release from plutonium production facilities, it has not mentioned that technetium has near zero background in nature (it is only produced by cosmic ray impact of molybdenum and can only be found in molybdenum rich ore). Therefor technetium is nearly exclusively produced by fission. Hence its presence can be a strong indication of nuclear weapons production. The diode laser ionization schemes described within this report are capable of detecting the most minute concentrations of radioisotopes. Extremely little sample is required to construct an accurate picture of nuclear activity and capabilities. A third obvious scenario involves cooperative monitoring for treaty verification with respect to NP and CW. The advantages over existing technology are the extreme sensitivity of the diode laser approach and the rapid analysis of solids for the LAMS approach. 


\section{M98051301}

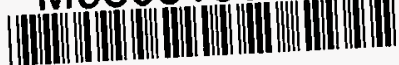

Report Number (14) PNNL--11420

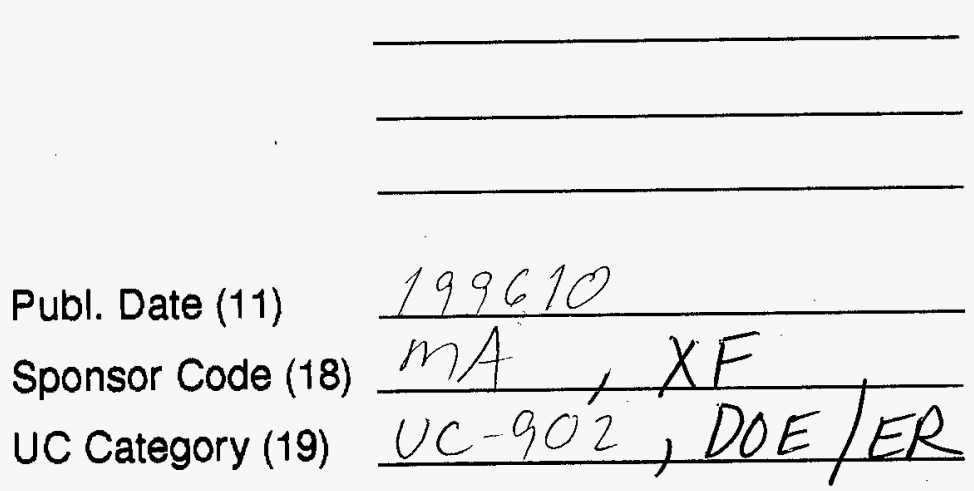

